\title{
Benefits Clfffs and the Financial Incentives for Career Advancement: A Case Study of a Health Care Career Pathway
}

David Altig

Federal Reserve Bank

of Atlanta
Elias Ilin

Federal Reserve Bank

of Atlanta and

Boston University
Alexander Ruder

Federal Reserve Bank

of Atlanta
Ellyn Terry

Federal Reserve Bank

of Atlanta and

University of Washington

\section{Primary issue:}

The authors investigate the financial disincentives to career advancement caused by benefits cliffs, which occur when earnings gains are offset by the loss of means-tested public benefits.

\section{Key findings:}

The authors develop a workforce development-focused methodology to study benefits cliffs and illustrate the financial incentives of a hypothetical young single mother of two children to advance from a low-wage occupation to higher-wage occupations. The lifetime financial return to career advancement for the mother is large. However, due to the loss of means-tested public benefits, the mother can be financially worse off in the short and medium term when she advances. The authors also show that individual career advancement can produce significant long-term financial gains for the public. Finally, the authors illustrate two policy interventions: a childcare subsidy phaseout that is gradual rather than sudden, and an application of transitional public benefits with asset mapping of financial resources.

\section{Takeaways for practice:}

To make informed training choices and plan for potential losses in public benefits, low-income individuals need dynamic tools that capture both short-run roadblocks and long-run gains to career advancement. Career counselors, caseworkers, and financial advisers need these tools to help advise clients on training choices and to plan for the phaseout of benefits. Policymakers can use these tools to align supportive services across and within funding streams, filling in resource gaps for clients and reducing short-term disincentives to train or seek a promotion. While up-front costs on programs that support career advancement may be expensive, the return to investment for the public can be significant.

\section{The Federal Reserve Bank of Atlanta's Community \& Economic Development (CED) Discussion Paper Series} addresses emerging and critical issues in community development. Our goal is to provide information on topics that will be useful to the many actors involved in community development-governments, nonprofits, financial institutions, and beneficiaries. Find more research, use data tools, and sign up for email updates at frbatlanta.org/commdev. 


\title{
Benefits Cliffs and the Financial Incentives for Career Advancement:
}

\section{A Case Study of a Health Care Career Pathway}

\begin{abstract}
:
Benefits cliffs, which occur when earnings gains are offset by the loss of public benefits, have long been recognized to create financial disincentives for low-income individuals to earn more income. Current approaches to inform individuals about these benefits cliffs focus on immediate employment income gains, which limit efforts to plan for short- and long-term career goals. In this paper, the authors develop a new methodology to study benefits cliffs in the context of career advancement. The authors illustrate the change in net financial resources for an individual pursuing the health care services career pathway from certified nursing assistant (CNA) to licensed practical nurse (LPN) to registered nurse (RN). Accounting for increases in taxes and the loss of public benefits, the authors show that a single mother with two children receiving maximum available public benefits can be financially worse off in the short and medium term when advancing from the entry-level CNA position. Over a lifetime, career advancement leads to large financial gains, creating a mismatch between short- and long-term individual financial incentives. The authors also calculate a large lifetime net public savings if the individual advances to the RN position. Finally, the authors illustrate two policy interventions: a childcare subsidy phaseout that is gradual rather than sudden, and an application of transitional public benefits with asset mapping of financial resources. The authors show how each of these interventions benefits a low-income parent seeking to earn credentials and advance up the economic ladder.
\end{abstract}

JEL classification: $138, \mathrm{~J} 08, \mathrm{~J} 24$

Key words: workforce development, benefits cliffs, human capital, skills, provision and effects of welfare programs, effective marginal tax rates

https://doi.org/10.29338/dp2020-01

\section{About the Authors:}

David Altig is executive vice president and director of research at the Federal Reserve Bank of Atlanta.

Elias Ilin is a research associate at the Federal Reserve Bank of Atlanta and a PhD candidate at Boston University. 
Alexander Ruder is a principal adviser in community and economic development at the Federal Reserve Bank of Atlanta.

Ellyn Terry is an economic policy analyst specialist at the Federal Reserve Bank of Atlanta and a PhD student at the University of Washington.

Acknowledgments: The authors thank Darryl Koehler, Laurence Kotlikoff, and Michael Leiseca for guidance on the use of The Fiscal Analyzer. We also thank Nick Espinosa, Jeffrey Fredericks, Sandra Giddy, and Carlis Williams for providing extensive details on the Continuum of Services model in Mississippi. Brittany Birken and Dale Brill offered valuable assistance with our analysis of the FATES graduated benefits phaseout program in Florida. Seth Hartig provided excellent feedback on early drafts. The views expressed here are the authors' and not necessarily those of the Federal Reserve Bank of Atlanta or the Federal Reserve System. Any remaining errors are the authors' responsibility.

Authors' note: Analysis in the earlier version of this paper underestimated annual out-of-pocket childcare expenses in Florida. We have corrected the calculation. In the earlier version, the worker is about $\$ 3,500$ better off in the medium term when advancing from the CNA to the LPN. In the revised version, the worker has a small negative disincentive to advance from the CNA to the LPN. No other substantive findings are changed.

Comments to the corresponding authors are welcome at alexander.ruder@atl.frb.org and ellyn.terry@atl.frb.org. 
In the United States, an increasing amount of attention is being focused on low rates of economic mobility, both intergenerational (how much a child's income as an adult is correlated with his or her parents' income at the same age) and intragenerational (how much an individual moves up the income distribution over his or her lifetime). ${ }^{1}$ Workforce development-job training and employment services that help individuals acquire credentials that employers demand, obtain employment, and increase their earnings-is an important component of broader strategies to promote both forms of economic mobility.

The widely adopted career pathways workforce development framework promotes economic mobility by focusing on career advancement, or the acquisition of skills that lead to wage increases or transitions into higher-paying occupations. However, recent literature reviews of longer-term career advancement outcomes have found mixed results (Bragg et al. 2019). Two recent evaluations of the Health Professions Opportunity Grant Program (HPOG) offer examples of the challenges that lowincome workers face when trying to advance in their careers through credential attainment. The HPOG is a career pathways grant program awarded to organizations that provide basic skills education, job training, and a variety of supportive services to Temporary Assistance for Needy Families (TANF) recipients and other low-income individuals. An evaluation of round one of the grant found that only 3 percent of certified nursing assistants advanced to higher-level training as a licensed practical nurse or a registered nurse (Loprest and Sick 2018). An evaluation of round two found that 6 percent of training participants enrolled in or completed multiple trainings at a more advanced career pathway level (Loprest and Sick 2019).

What prevents individuals from earning credentials to advance from entry-level to higher-paying occupations? In this discussion paper, we investigate one possible barrier to career advancement: the loss of financial resources due to income exceeding eligibility requirements for public benefit programs. Some low-income workers, particularly those with children, face a disincentive to pursue a higherpaying job through so-called benefits cliffs, which arise when earnings gains are offset by the loss of means-tested public financial supports, such as childcare subsidies. These benefits cliffs can be so severe that low-income workers may be temporarily better off financially by not advancing to take a higherpaying job.

We illustrate the short-term, medium-term, and long-term financial trade-offs from the perspective of a hypothetical individual considering different occupational choices on a health care career pathway (described below). In particular, we ask, "What is the all-in financial benefit of transitioning from a near minimum wage occupation to higher-paying occupations in the health care industry for a specific case of a single mother of two children currently receiving a full complement of public benefits?" (In their description of the HPOG 2.0 evaluation, Loprest and Sick [2019] indicate that 91 percent of participants were female; 78 percent were never married, widowed, or divorced; and 69

\footnotetext{
${ }^{1}$ For example, see the extensive work by Raj Chetty and colleagues (Chetty et al. 2017), the Pew Charitable Trusts (Butler, Bleach, and Winfree 2008), and the Federal Reserve Bank of St. Louis and the Board of Governors of the Federal Reserve System (Brown et al. 2017).
} 
percent had at least one child. Thus, our hypothetical earner fits the profile of the modal HPOG participant.)

Our analysis reveals a complex set of financial incentives for career advancement. Without accounting for tax increases or benefits loss, we show a clear financial incentive for career advancement from both short-term and long-term perspectives. However, tax increases and benefit losses change these incentives materially. In the short term, we find that the individual in our case study is financially worse off when advancing from the entry-level CNA position to the midlevel LPN position and has no positive incentive to advance from the LPN position to the more advanced RN position. In the medium term, she faces no financial incentive to advance from the CNA to the LPN and is financially worse off when advancing from the LPN to the RN. Despite these shorter-term losses, she is significantly better off financially in the long term advancing up any step in the career pathway.

We also examine career advancement from the perspective of government finances. Programs that support career advancement for individuals on public benefits not only help individuals by increasing their earnings, but they can benefit the larger public as well. These public benefits are taxpayer funded, so helping individuals advance up a career pathway has implications for government finances. We calculate the net savings to the public (tax revenue minus public benefits transfers) from career advancement using The Fiscal Analyzer (TFA), developed in Altig et al. (2019), Auerbach et al. (2016), and Auerbach et al. (2017). TFA is a detailed life-cycle, consumption-smoothing program that incorporates borrowing constraints and all major federal and state tax provisions and benefits programs.

Calculated for the lifetime of our hypothetical single mother, net public savings for federal and state governments combined are significant for all steps in the career pathway. Assuming the lowincome mother in our case study receives a variety of public benefits, including childcare subsidies and housing vouchers, we calculate that the public saves (in present value) approximately $\$ 409,000$ over the lifetime if she advances up the full career pathway. ${ }^{2}$ In a second analysis, we relax the assumption that the individual receives childcare subsidies and housing vouchers. ${ }^{3}$ In this case-which is more representative of the typical public assistance recipient-the savings to taxpayers are still substantial. In our calculations, savings to the public (in present value) are approximately $\$ 283,000$ over the lifetime if she advances up the full career pathway.

Our argument is not that benefits cliffs alone explain why few individuals advance up career pathways through credential attainment. Rather, we seek to show that individuals similar to those enrolled in the HPOG program may face a complex set of financial incentives to advance beyond entrylevel positions. Career pathways programs may have limited success if participants ultimately have little short- and medium-term financial incentives to advance, or if short-term financial needs prevent them from basing advancement decisions on the long-term financial gains associated with career advancement.

\footnotetext{
${ }^{2}$ When calculating present-value figures, we discount inflation-adjusted future gains and losses at 6.5 percent per year.

${ }^{3}$ As we explain below, these benefits programs are allocated through a lottery process and often have lengthy waiting lists, meaning relatively few who are eligible receive the benefit.
} 
Our workforce development-based methodology to study benefits cliffs described in this paper is part of a larger Federal Reserve Bank of Atlanta initiative to study low-income families' financial incentives for career advancement. The initiative includes quantitative and qualitative research on career choice and financial planning with career counselors, caseworkers, and policymakers. In addition, we are partnering with select policymakers, educational institutions, and service providers to better understand how benefits cliffs impede career advancement and apply our research to inform solutions. A major part of this initiative is the development of an interactive tool designed to educate individuals on the financial returns to education and career advancement. The tool, called CLIFF (Career Ladder Identifier and Financial Forecaster), provides a full financial picture of career choice, including possible short-term declines in resources while in school due to loss of employment income or a sudden loss of benefits (benefits cliffs) that may come with higher employment income. Information about this initiative can be found at www.frbatlanta.org/advancing-careers.

This paper proceeds as follows. First, we review the career pathways framework in workforce development and describe how it is intended to promote career advancement. Second, we show how incremental increases in income cause the loss of public benefits and have an impact on a family's net financial resources. Third, we use our health care pathway case study to demonstrate how the loss of public benefits can distort incentives to acquire more skills and advance up a career pathway. Fourth, we calculate the net public savings to skill acquisition, highlighting a potential disconnect between private and public incentives. Finally, we apply our methodology to illustrate how two real-world policy proposals can mitigate benefits cliffs and improve the financial incentives for career advancement.

\section{The Career Pathways Framework in Workforce Development}

The career pathways framework (CPF) is increasingly used in workforce development to meet businesses' demand for a skilled workforce and to help low-income individuals advance to higher-paying occupations. In brief, a career pathway is a sequence of educational credentials that typically begins with a credential qualifying someone for an entry-level occupation. Additional credentials in the sequence lead to progressively higher-paying occupations. The following definition from King and Prince (2015, page 202) captures key features of the CPF:

These [career] pathways identify entry and exit points along the way, from which individuals can enter postsecondary course work, exit into the labor market with a marketable skill and certificate to vouch for it, and reenter at a later point, earning credits that "stack" toward the completion of a degree.

Essential features of career pathways are alignment with industry demand, connection, and advancement. Career pathways align education and training with employment in a specific sector (such as health care); career pathways connect education and training as a sequence of well-defined steps, enabling individuals to more easily enroll in additional training for more advanced sector-specific skills or credentials; and career pathways help individuals advance in their careers. Individuals may begin at a low-wage entry-level position, but the pathways model 
presumes that they advance to jobs that pay higher wages, offer benefits, and provide greater financial stability.

Numerous organizations have adopted or are developing programs based on the CPF. Three major federal education and training laws include the CPF: the Workforce Innovation and Opportunity Act (WIOA), the Carl D. Perkins Career and Technical Education Act, and the Higher Education Act (Cielinski 2019). Numerous states and localities have developed career pathways tailored to local industries. Three federal departments-Health and Human Services, Labor, and Education-are funding career pathways research (Abt Associates, Inc. 2014, footnote 3).

Is the CPF successful as a career advancement strategy beyond entry-level positions? The evidence is inconclusive. Numerous evaluations find that the CPF has positive impacts on employment and earnings. ${ }^{4}$ However, Eyster and Gebrekristos (2018) note that most of this evidence is focused on the initial entry-level step of the career pathway. A 2019 literature review reports that four out of five career pathways evaluations show no difference in additional college enrollment or completion rates after initial enrollment in the career pathways program, relative to a control group; results for additional postsecondary training, credential attainment, and employment retention were mixed (Bragg et al. 2019).

As discussed in the introduction, a 2018 evaluation of the Health Profession Opportunity Grant Program (HPOG) 1.0 finds limited evidence for career advancement in a career pathways program. In the program, over 9,600 individuals completed training for the lower-wage certified nursing assistant occupation, making it the program's most popular health care training choice. The HPOG evaluation also examined whether CNA training led to higher-paying jobs over time. A striking statistic from the report is that only 3 percent of CNA training completers advanced to train as a higher-paying licensed practical nurse or registered nurse (Loprest and Sick 2018, page 23). The 2019 evaluation of HPOG 2.0-a modified version of HPOG 1.0 that includes more individuals, more career paths, and enhanced supportive services - reports that approximately 6 percent of training participants started or completed a more advanced training program (Loprest and Sick 2019). ${ }^{5}$

Why do so few individuals advance along the health care career pathway? One answer, according to the HPOG 1.0 evaluation, is that low-income individuals face numerous barriers to changing careers, such as the need to combine work and school and cover childcare costs (Loprest and Sick 2018). ${ }^{6}$ Evaluations of other career pathway programs find similar barriers, including, for example, a lack

\footnotetext{
${ }^{4}$ See King and Prince (2015) for a review.

${ }^{5}$ The HPOG 2.0 evaluation also uses a broader definition of career advancement and finds that 28 percent of health care training participants advanced. The broader definition includes individuals who obtain multiple entrylevel credentials (rather than an entry-level and a more advanced credential) as well as participants who started the program in a mid- or high-level credential program.

${ }^{6}$ Other reasons given for the finding of a low advancement rate include the relatively short length of the HPOG 1.0 study (five years). It is possible that students advanced after the study follow-up period. In addition, not all HPOG study sites include training beyond the CNA, so individuals would have had to enroll in another institution for advanced training.
} 
of time or transportation, inability to access affordable childcare and financial aid, feelings of guilt about spending time away from children and family, and struggles navigating complex academic prerequisite requirements for admission into more advanced training (Seefeldt, Engstron, and Gardiner 2016). Hence, some workforce development experts advise that "[c]areer pathways programs may need to address barriers before helping people access and complete more advanced education and training" (Eyster and Gebrekristos 2018, page 4).

The next section examines the various benefits that a hypothetical single mother stands to lose as her income grows, in addition to the additional taxes she would have to pay. We call this hypothetical single mother Leia. We illustrate how at some points along the income continuum, abrupt reductions in net benefits can constitute a strong disincentive for Leia to earn more.

\section{Benefits Cliffs: A Review}

Low-income workers may be eligible for and often receive a variety of public benefits and tax credits with income eligibility thresholds. As has long been recognized in the literature, the gradual or sudden loss of these benefits as income rises is an implicit marginal tax on employment income (Albelda and Carr 2017; Bingulac, Carey, and Crandall 2017; Camardelle 2019; Congressional Budget Office 2015; Florida Chamber Foundation 2017; Florida Children's Council 2018; Romich, Simmerlink, and Holt 2007; Wood et al. 2018). These implicit marginal tax rates can be high when individuals lose financially large benefits, such as housing subsidies, or when they lose eligibility for multiple programs at or near the same point in time. In fact, in some cases, marginal tax rates can exceed 100 percent-for an additional $\$ 1$ in employment income, the individual pays back more than $\$ 1$ accounting for taxes and benefits loss. $^{7}$

The top panel of Figure 1 illustrates benefits cliffs for a hypothetical parent, Leia, who has two children, ages four and six, and lives in Miami, Florida. On the horizontal axis is Leia's annual employment income; on the vertical axis is Leia's annual net resources. We define annual net resources as the difference between a family's total financial resources minus a set of basic expenses. Financial resources include after-tax employment income, state and federal tax credits, Temporary Assistance for Needy Families (TANF) cash assistance, and the estimated value of all public benefits received. ${ }^{8}$ Expenses include taxes paid, rent payments, health care premiums, childcare expenses, and food expenses. Our list of basic expenses is not exhaustive since we include only those expenses that can be reduced by the public benefits described below.

\footnotetext{
${ }^{7}$ See David Altig and Laurence J. Kotlikoff, "A Different Type of Tax Reform." Macroblog, March 22, 2019. https://www.frbatlanta.org/blogs/macroblog/2019/03/22/a-different-type-of-tax-reform.

${ }^{8}$ Our definition of financial resources does not include the value of assets accumulated over time.
} 


\section{Figure 1: Benefits Cliffs}

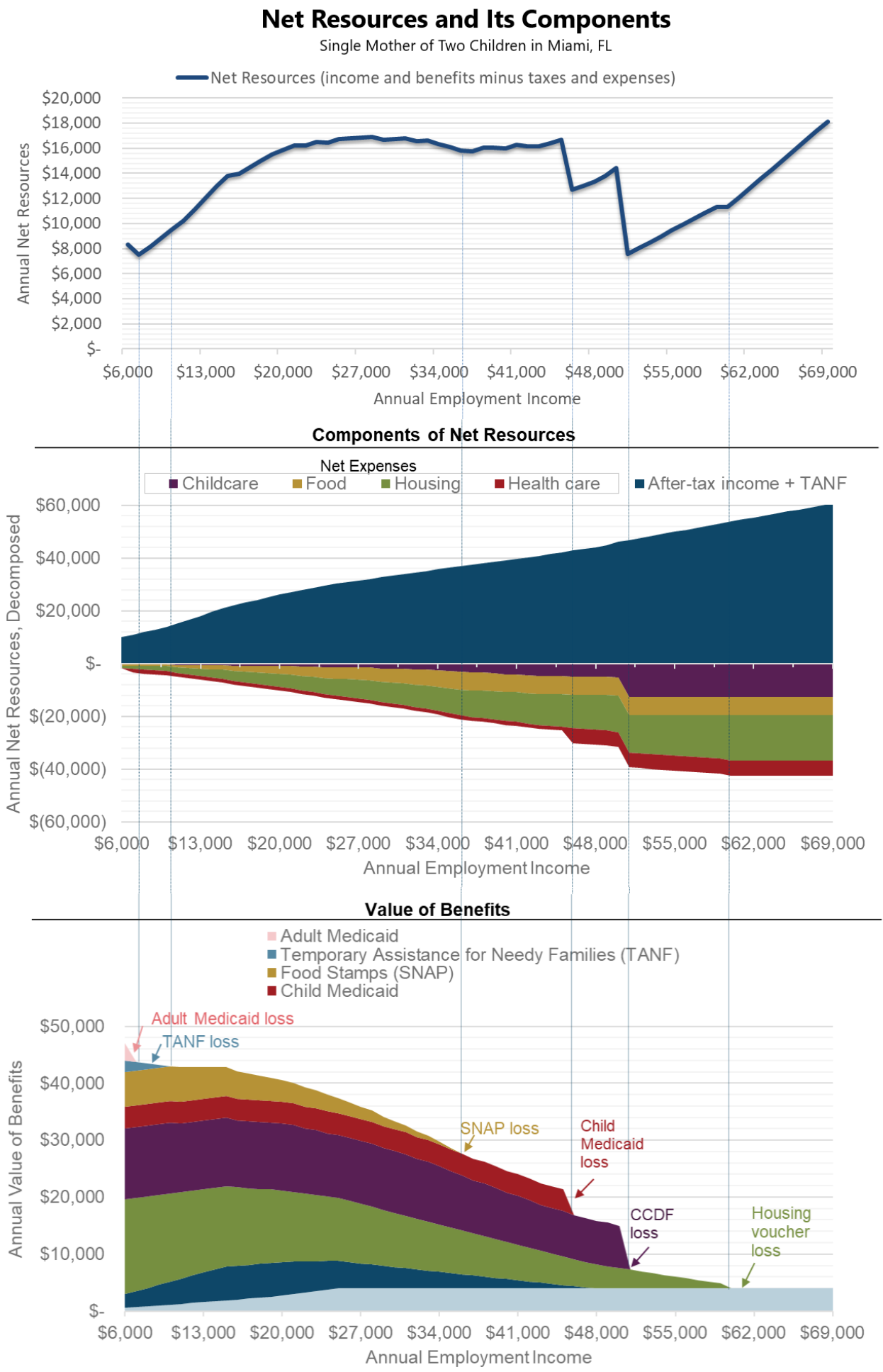

Notes: Assumes single mother of two children (ages four and six) receiving all major federal and state benefits for which she is eligible. See appendix for details. All values are in current-year dollars. Sources: authors' calculations and The Fiscal Analyzer 
The top panel demonstrates how annual net resources vary by level of employment income. As employment income increases, two changes occur. First, the total tax liability rises. Second, benefits eligibility changes, which increases out-of-pocket net expenses. The middle panel of the figure decomposes the annual net resources at any level of employment income into net negative expenses and positive income after taxes, inclusive of tax credits and TANF receipt. Details for how each net expense is calculated can be found in the appendix. The bottom panel shows the income levels at which the loss of public benefits occurs, along with the estimated value of each program at different levels of income. Vertical lines across all three panels connect the benefits cliffs shown in the top panel to the increases in net expenses due to loss of benefit(s) (middle panel) and the values of benefits loss (bottom panel).

As the top panel in Figure 1 shows, when Leia's annual employment income increases from about $\$ 6,000$ to $\$ 45,000$, annual net resources increase, though at a generally decreasing rate and at some points actually decrease. ${ }^{9}$ Beyond $\$ 45,000$ in annual earnings, several larger benefits cliffs appear. At approximately $\$ 46,000$ in income, Leia's children are no longer eligible for child Medicaid, which is the Children's Health Insurance Program (CHIP). ${ }^{10}$ The family then loses childcare assistance at approximately $\$ 51,000$ in employment income. Leia's loss of childcare subsidies is the largest benefits cliff she faces. At $\$ 51,000$ of employment income, Leia's net resources are $\$ 7,560$ per year, which is about the value of net resources when her employment income was only $\$ 7,000$ per year. Thus, in terms of net resources, she is about as well off financially earning $\$ 51,000$ per year as she was earning only $\$ 7,000$ per year. In summary, the consequences of these benefits cliffs are severe.

Figure 1 illustrates how higher earnings lead to a loss of public benefits and tax credits that could leave the family worse off financially when taking a higher-paying job. However, this presentation of benefits cliffs has limited applicability as a guide for career choice and financial planning. For career choice, the top panel in Figure 1 does not easily allow individuals to understand the trade-offs inherent in training choices. Accounting for benefits cliffs, will the long-term benefits exceed the short-term costs? How does the wage growth of one career path compare to another, in both the short term and over the lifetime?

Figure 1 also has limited applicability for short- and long-term financial planning because the presentation does not account for the passage of time. It takes time to earn credentials and advance up a career pathway; for some career pathways, individuals may spend years moving back and forth between training programs and full-time employment. As this time passes, life circumstances-such as an individual's age and changes in household size (through divorce or children leaving the home as adults) - affect both benefits receipts and basic household expenses like housing, childcare, food, and

\footnotetext{
${ }^{9}$ At $\$ 7,000$, a single parent is no longer eligible for Medicaid. Florida chose not to expand Medicaid coverage under the Affordable Care Act. Under Florida law, adults with dependents are not covered unless they make less than 33 percent of the federal poverty thresholds.

${ }^{10}$ Upon expiration of CHIP eligibility, we assume that our hypothetical mother purchases the family health insurance plan at her place of employment. This leads to an increase in her net health insurance costs (the dark red section of the middle panel in Figure 1).
} 
health care. For example, if an individual with young dependents enrolls in occupational training, she may find that by the time she completes school her children no longer require after-school care. Without the need to pay for after-school care, the parent no longer has to consider the childcare benefits cliff. This could potentially change the trade-off between benefit losses versus greater income she weighs when deciding whether or not to move up a career path.

\section{Leia on the Health Care Services Career Pathway: A Case Study}

We now examine how benefits cliffs affect the financial incentives of career advancement over the lifetime using the hypothetical mother described in the previous section as a case study. As noted earlier, we refer to the young mother as Leia.

We assume that Leia currently earns $\$ 8.92$ per hour at a full-time job selling popcorn in a movie theater, but wants to train for an occupation that provides her with higher earnings. ${ }^{11}$ At the advice of a friend, she visits a federally funded career center that provides employment services and training funds to qualified individuals. Leia meets with a career counselor to assess her skills and career interests. Based on Leia's skill and interest assessments, the counselor tells Leia about the health care career pathway from certified nursing assistant to licensed practical nurse to registered nurse. Health care is a large and growing sector of the local economy. Local labor market information shows that health care employers have numerous openings for CNAs, LPNs, and RNs. Thus, Leia is confident she will be able to find a higher-paying job soon after obtaining a health care credential.

CNA training typically is short term in duration-technical colleges in Miami-Dade County offer a full-time program. CNA certification also typically leads to full-time employment, since area hospitals have high demand for CNAs. However, it is also a relatively low-paying job (\$12.51 per hour). Therefore, the counselor encourages Leia to begin with CNA training as it leads to quick employment within the health care sector, and then return to school for additional training as an LPN (a one-year full-time program) and possibly even an RN (a two-year full-time program). To inform Leia about this decision, the counselor provides her with a career pathway model similar to the image in Figure 2.

\section{Figure 2: The Health Care Services Pathway}

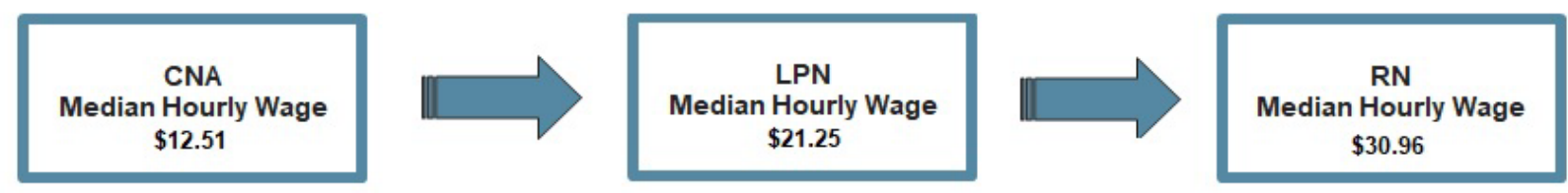

Source: Median hourly wages for each occupation are from the U.S. Bureau of Labor Statistics. Occupational Employment Statistics for the state of Florida, May 2018

\footnotetext{
${ }^{11}$ We choose concessions to illustrate a real low-wage occupation in Miami, Florida. The amount is just above the Florida minimum wage of $\$ 8.46$ per hour. We choose the CNA-LPN-RN pathway because it is a widely recognized career pathway in an important industry sector. In many regional economies, health care is a growing sector that employs a large number of workers, creating demand for more nurses. Our results are not significantly different when looking at other career paths with similar earnings progressions.
} 
Will Leia be better off financially by moving up the health care services career pathway? Figure 2 suggests that the answer is yes. Median wages increase at each incremental stage of the pathway. However, the median wage statistics in Figure 2 do not account for increased taxes, the loss of benefits from crossing eligibility thresholds, or the lost income from reducing work hours while enrolled in school. They also do not include a longer-term perspective on earnings growth across the different careers. For example, how much more will an LPN earn over his or her lifetime compared to a CNA, considering not only decreases in benefits receipt but also any costs associated with school, and the opportunity cost from forgone employment earnings? ${ }^{12}$

Figure 3 shows annual after-tax income over time for four career paths: the concessions job for Leia's entire life (red line); the concessions job to the CNA (orange line); the concessions job to the CNA to the LPN (green line); and, finally, the full progression from the concessions job to the CNA to the LPN to the RN (blue line). In each career path, we assume that Leia enrolls in training full-time and works part-time as she acquires the credential required for the next occupation on the pathway. The orange shaded area indicates full-time enrollment in CNA training for the CNA, the LPN, and RN career paths. The green shaded area indicates full-time enrollment in the one-year LPN training program for the LPN and RN career paths (Leia works part-time as a CNA while in LPN training). The blue shaded area indicates full-time enrollment in the two-year RN training, during which Leia works part-time as an LPN. A local technical college offers the CNA, LPN, and RN programs, and we assume a combination of Pell grants or WIOA training funds cover tuition expenses. For each occupation, Leia starts at an entry-level wage, which we assume is equal to the 25 th percentile of local wages. The wage grows over time to the 75th percentile. ${ }^{13}$

Leia will start at an entry-level wage of $\$ 11$ and work up to $\$ 14$ an hour by the time she is 44 (before taxes) as a CNA. If she advances to an LPN, her pay will increase from \$18 to \$24 an hour. Advancement to an RN means her pay will increase from $\$ 27$ to $\$ 37$ an hour. Consistent with the median wage statistics in Figure 2, the LPN and RN career choices earn more than the CNA in both the short and long term. The exception is a dip in earnings when Leia works part-time while enrolled in training (shaded columns). In this period, she earns less as a part-time CNA or part-time LPN than she would as a full-time concessions worker.

\footnotetext{
${ }^{12}$ Despite these limitations, the presentation of median or average earnings is still a common way to inform individuals about potential future earnings in different career choices.

${ }^{13}$ For more details on income path and career choice assumptions, see the appendix.
} 
Figure 3: Annual After-Tax Income

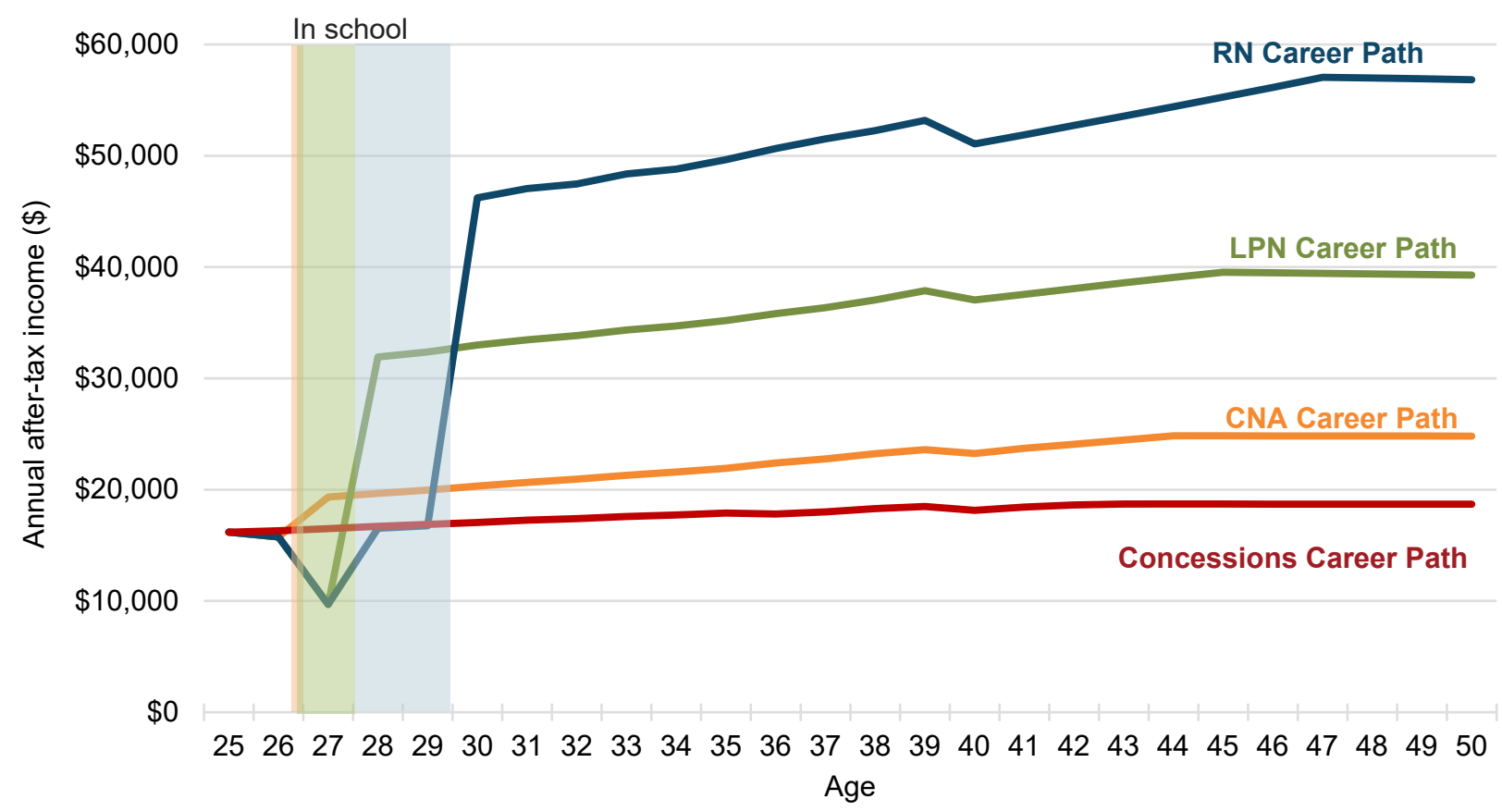

Notes: Shaded areas indicate a decrease in earnings due to full-time training enrollment and part-time employment at age 26 for the CNA, LPN, and RN career path lines; age 27 for the LPN and RN career path lines; and ages 28 and 29 for the RN career path line. Taxes increase substantially at age 40 , when Leia no longer has dependents to claim. All values are in current-year dollars.

Sources: authors' calculations and The Fiscal Analyzer

\section{Incentives and disincentives for career advancement}

For individuals like Leia, employment income may not be enough to meet basic family expenses, including food, housing, childcare, and health insurance, without the assistance of public benefits programs. ${ }^{14}$ In our analysis, Leia receives a number of public benefits programs that help her meet basic expenses. We list the specific tax credits and benefits programs Leia receives in Table 1.

We assume Leia is enrolled in all the listed federal and state programs for which she is eligible. This is an admittedly strong assumption. Individuals may not apply for programs even though they meet the eligibility criteria. Even if individuals apply for each program, they may not receive all the benefits for which they are eligible. Housing vouchers and childcare support, for example, tend to be subject to supply constraints. Chien (2017) estimates that in 2013 only 16 percent of eligible children received a subsidy for childcare. Similarly, according to the Congressional Budget Office (2018), only one in four of the 20 million households that qualify for federal rental assistance actually receive the subsidy.

\footnotetext{
${ }^{14}$ We only include expenses that these government benefit programs can potentially affect. An expanded list would likely include items like clothing, transportation, and household goods. These items can cost several thousand dollars per year. See appendix for all assumptions about living expenses.
} 


\section{Table 1: Taxes and Benefits Programs for Leia's Case}

\begin{tabular}{|c|c|}
\hline \multirow[t]{6}{*}{ Taxes } & Corporate Income Tax (state and federal) \\
\hline & Employer Payroll Tax (federal) \\
\hline & $\begin{array}{l}\text { Federal Insurance Contributions Act (FICA) Tax } \\
\text { (federal) }\end{array}$ \\
\hline & Medicare Part B Premiums (federal) \\
\hline & Personal Income Tax (federal and state) \\
\hline & Sales Tax (state) \\
\hline \multirow[t]{10}{*}{ Public Benefits Programs } & Affordable Care Act (ACA) Subsidy (federal) \\
\hline & Childcare Assistance (federal and state) \\
\hline & Child Tax Credit (CTC) (federal) \\
\hline & Earned Income Tax Credit (EITC) (federal and state) \\
\hline & Medicaid (federal and state) \\
\hline & Medicare (federal) \\
\hline & Section 8 Housing Vouchers (federal) \\
\hline & Social Security Retirement Benefits (federal) \\
\hline & Supplemental Nutrition Assistance Program (federal) \\
\hline & Temporary Assistance for Needy Families (federal) \\
\hline
\end{tabular}

Notes: See appendix for detailed assumptions for each tax and public benefits program. Corporate income tax is the tax on corporate profits. Individuals pay these taxes in the form of smaller dividend receipts. The FICA tax includes Social Security and Medicare taxes withheld by employers. Florida does not have an income tax, so only federal taxes are included in this case. Local sales taxes are not included. Florida does not have an EITC. We assume 61 percent of Medicaid costs are paid for by the federal government and 39 percent are paid for by the state government. We assume 73 percent of CHIP costs are paid for the federal government and 27 percent are paid for by the state government. Source: authors' calculations and The Fiscal Analyzer

Figure 4 shows Leia's financial incentives for career advancement after factoring in the receipt of these public benefits programs, taxes, and basic expenses. Figure 4 show a far more complex picture than the nearly linear and upward sloping after-tax employment paths in Figure 3. Changes in benefits, employment income, taxes, and expenses create a far more variable financial trajectory. Across all four career paths, annual net resources rise, drop, or remain relatively flat for multiple years at a time. In the short to medium term along the CNA and LPN paths, net resources growth is nearly flat or negative up to age 35, at which point net resources decrease considerably. At certain ages, Leia is actually better off financially as a concessions worker than as a CNA or an LPN. At age 36, the CNA path net resources drop below net resources for the concessions job, mainly because the concessions path gains eligibility for the ACA subsidy at age 36. For one year at age 39, the LPN drops below both the CNA and concessions jobs because Leia's higher income makes her ineligible for all public benefits; however, at age 40, her second child leaves home, which reduces total expenses and allows net resources to once again exceed the CNA and concessions paths. ${ }^{15}$

\footnotetext{
${ }^{15}$ For more details about the annual net resources amounts in Figure 4, see the appendix, where we disaggregate annual net resources into benefits, expenses, and taxes by age and career path.
} 


\section{Figure 4: Annual Net Resources over Time}

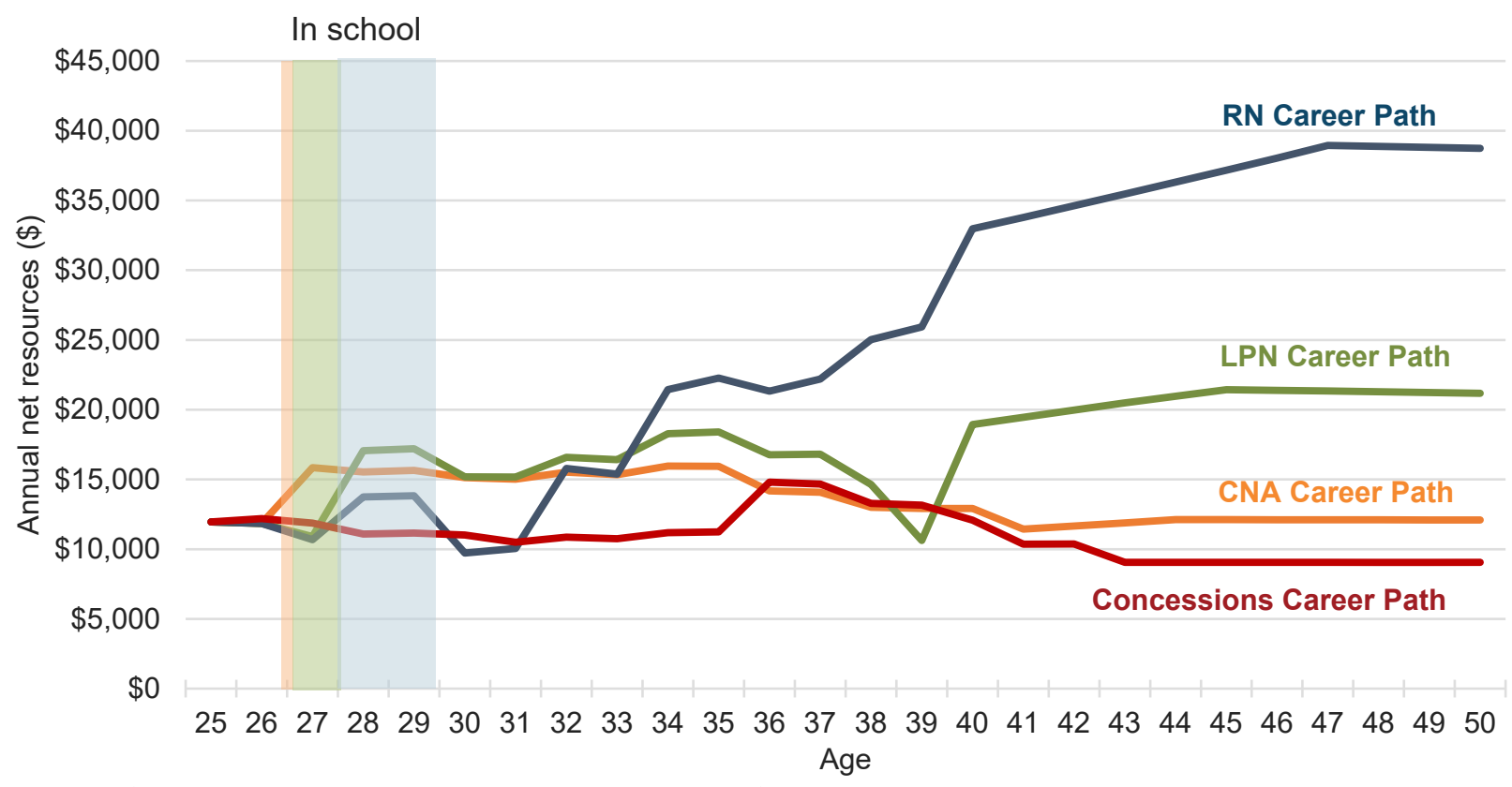

Note: We define annual net resources as employment income and benefits minus taxes and expenses. All values are in current-year dollars. Sources: authors' calculations and The Fiscal Analyzer; in the appendix, we disaggregate annual net resources and show the value of public benefits, taxes, and expenses over time and by career path

Sources: authors' calculations and The Fiscal Analyzer

The financial incentive to career advancement across the career paths is far smaller when measured in annual net resources compared to after-tax income. For example, Leia earns an additional $\$ 37,000$ more in after-tax income between the ages of 25 and 33 as an LPN compared to a CNA. However, in terms of net financial resources, there is no difference between the LPN path and the CNA path.

Even the highest-paying occupation on this career pathway-the RN-fails to make Leia better off in the short to medium term. Her annual net resources decline immediately upon starting as an RN (age 30) because she loses access to SNAP, childcare assistance, and the Earned Income Tax Credit. The value of her housing voucher also drops substantially, since her out-of-pocket contribution increases as her income rises. With her new salary as an RN, she also loses access to CHIP, which increases her outof-pocket health insurance costs because she enrolls her children onto her health care plan at work. Overall, she is financially better off staying as a CNA or an LPN between ages 25 and 33 than becoming an RN.

We illustrate the incentives for career advancement across different periods in a simplified manner in Figure 5. The figure shows the short-term (ages 25 to 27), medium-term (ages 25 to 33), and long-term (lifetime) incremental gains in annual net resources for each career path transition. The shortterm and medium-term perspectives do not offer a large financial incentive for career advancement- 
particularly for the CNA to LPN transition or the LPN to RN transition. The short-term CNA to LPN transition and the medium-term LPN to RN transition both result in a loss of net resources. Despite these shorter-term losses, there are large advantages to both of these career advancements when calculated over a lifetime. The CNA occupation allows Leia to earn $\$ 39,000$ more in annual net resources over her life, compared to the concessions job. If she continues on to become an LPN and then an RN, she gains an additional $\$ 144,000$ (present value) in annual lifetime net resources. ${ }^{16}$

\section{Figure 5: Short-, Medium-, and Long-Term Incentives for Advancement}

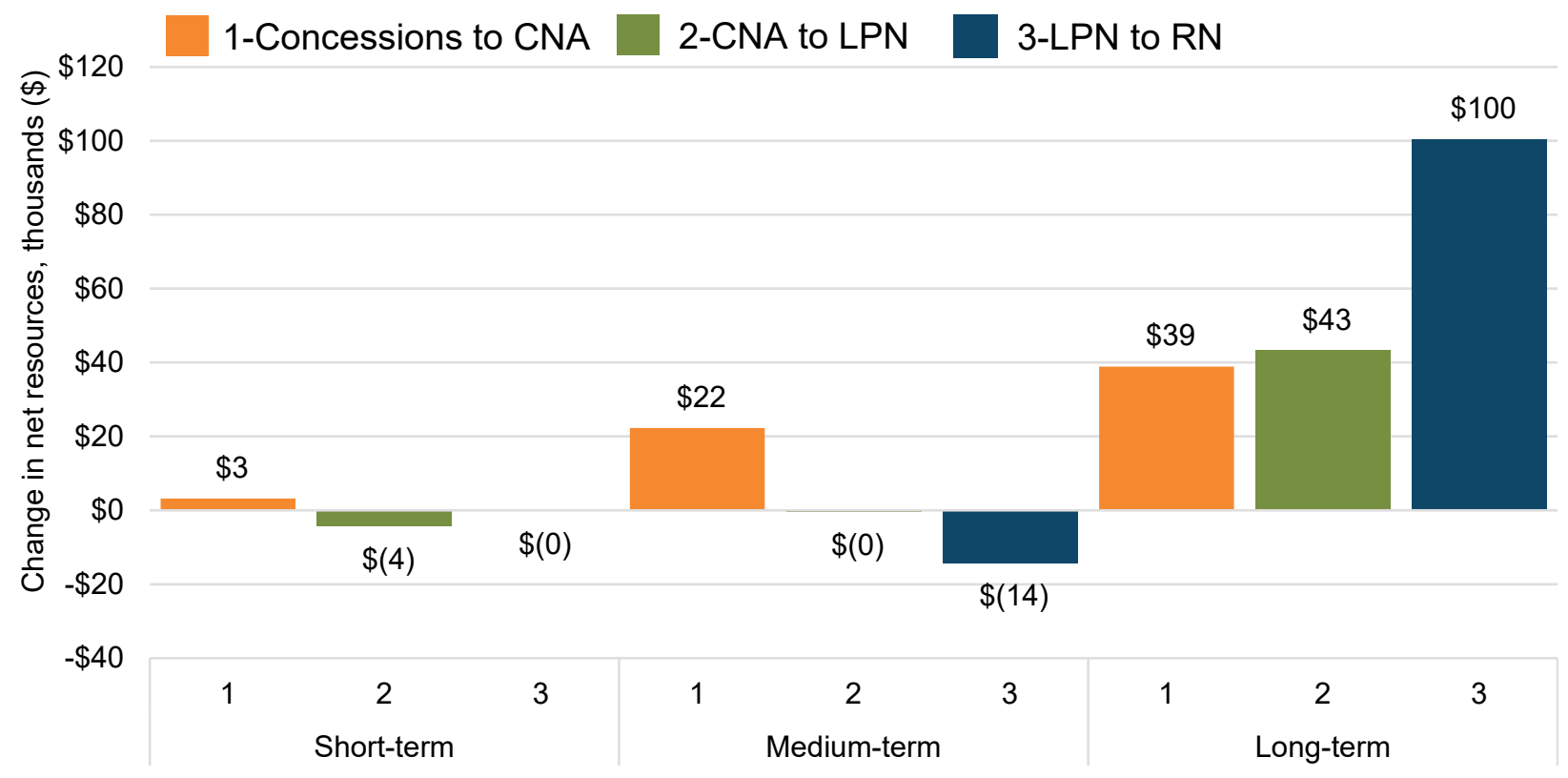

Notes: Short-term indicates ages 25 to 27, medium-term indicates ages 25 to 33 , and long-term indicates ages 25 to the end of life. Figures are in present-value terms. Numbers in parentheses indicate negative values.

Sources: authors' calculations and The Fiscal Analyzer

\section{Net public savings of career advancement}

Many benefits programs are intended to provide short-term financial support on a path to selfsufficiency (for able-bodied working-age adults). Taxpayers spend a considerable amount of money to fund these benefits. When individuals advance to higher-paying jobs, they likely require less public assistance and pay more in taxes, which provides gains to taxpayers relative to individuals remaining on public benefits or in low-wage jobs. Thus, in our case study, if Leia does not pursue higher-paying

\footnotetext{
${ }^{16}$ The $\$ 144,000$ figure represents the incremental long-term gain of transitioning to the LPN and RN from the CNA. It is calculated by summing the long-term bar at the CNA to LPN transition and the long-term bar at the LPN to RN transition.
} 
occupations because of shorter-term disincentives, the financial consequences to her and to taxpayers are significant.

Figure 6 shows the difference in short-term, medium-term, and long-term net public returns for each step in the career path. Net public returns are the sum of all taxes received from Leia's employment income minus the sum of all public benefits paid to Leia. The measure shows the incremental gain to taxpayers for each occupational transition. At every step on the career pathway, taxpayers gain in the medium term and over the lifetime. The lifetime gains of moving from the concessions job to CNA is a present-value net gain of $\$ 100,000$. Moving from CNA to LPN to RN is a present-value net gain of $\$ 309,000$. The savings to taxpayers over Leia's lifetime are approximately $\$ 409,000$ when Leia advances from working concessions in a movie theater to an $\mathrm{RN}$, on a discounted present-value basis. ${ }^{17}$

Taxpayers do not have to wait a lifetime to realize these returns. The medium-term returns are positive for the concessions to CNA transition $(\$ 19,000)$, the CNA to LPN transition $(\$ 63,000)$, and the LPN to RN transition $(\$ 30,000)$. In the short-term period, only the CNA transition has net returns above zero (after rounding to the nearest thousand).

Figure 6: Short-, Medium-, and Long-Term Net Public Returns Advancement

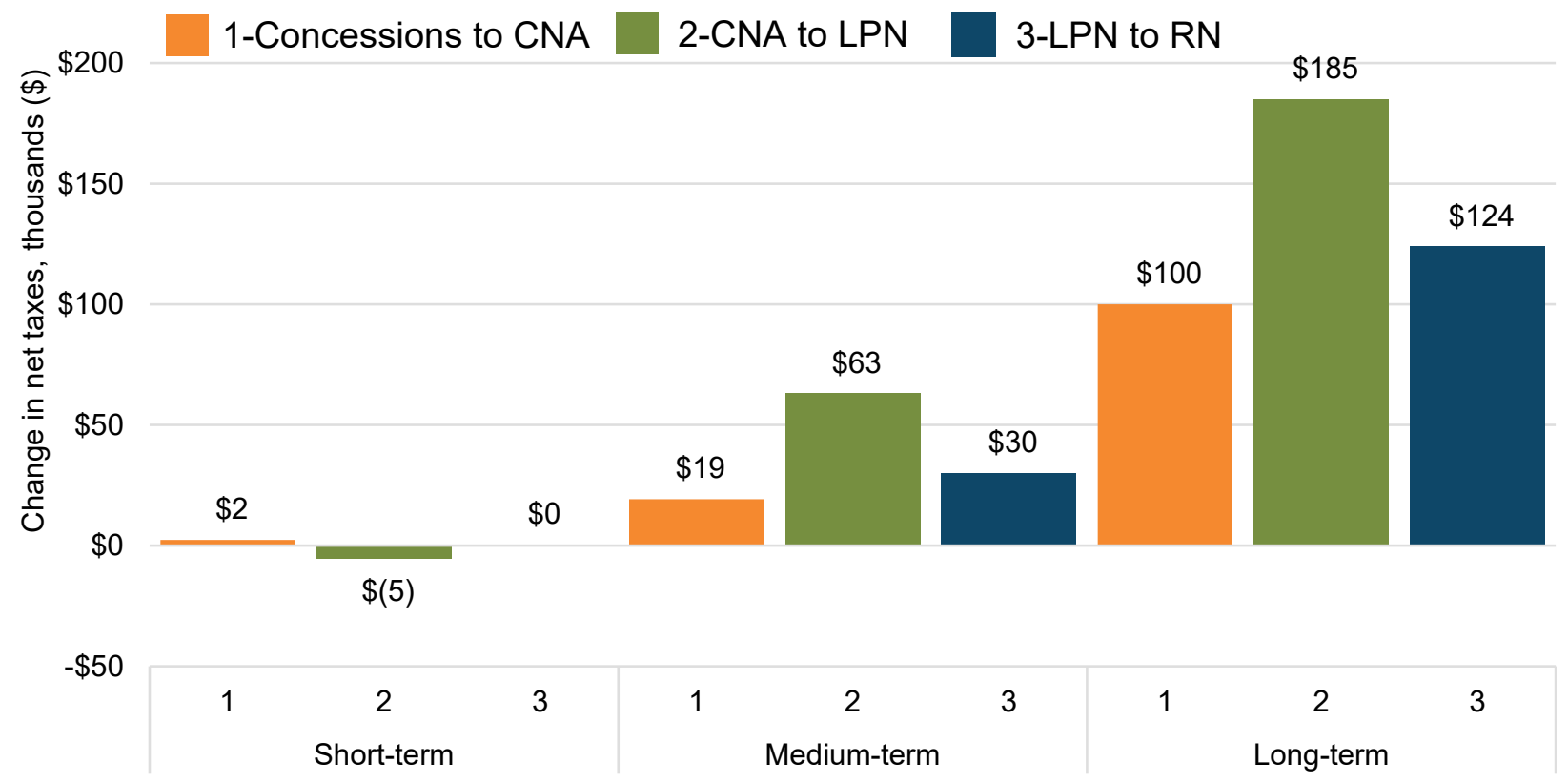

Notes: Short-term indicates ages 25 to 27 , medium-term indicates ages 25 to 33 , and long-term indicates ages 25 to the end of life. Figures are in present-value terms. Numbers in parentheses indicate negative values.

Sources: authors' calculations and The Fiscal Analyzer

\footnotetext{
${ }^{17}$ Because most of the funding of benefit programs comes from federal sources, the state of Florida receives a relatively small portion of these savings generated at each transition. See the appendix for full details.
} 
These estimates of net public returns to the public should be considered in the upper range of potential savings. As previously discussed, relatively few eligible families receive childcare subsidies or rental housing assistance due to supply constraints. Thus, the example above represents an atypical case. In addition, for the public to gain when Leia transitions off housing or childcare programs, we would have to assume that no one from the waiting list takes Leia's place.

We examine the sensitivity of our estimates to these assumptions by analyzing a case where Leia does not receive housing or childcare assistance. ${ }^{18}$ Figure 7 replicates the net public returns analysis in Figure 6, but it assumes that Leia does not receive either childcare subsidies or housing subsidies. Both the medium- and long-term gains are smaller, though still positive. The lifetime gains to the public from advancing from concessions to $\mathrm{RN}$ are $\$ 283,000$, which is about a 31 percent decrease from the net returns under the full-benefits assumption. The gains are still large without the childcare and housing benefits programs because of gains in federal tax revenue, which are unaffected by the use of childcare and housing subsidies. With each transition, we estimate substantial gains in taxes paid by both Leia and her employer. When she moves from CNA to RN, we estimate she pays $\$ 91,000$ more in federal taxes (including subtractions for the EITC and CTC) and that her employer pays $\$ 32,000$ more in employer payroll taxes. Further, an additional $\$ 32,000$ is withheld from her paycheck for FICA. ${ }^{19}$

\footnotetext{
${ }^{18}$ In the appendix, we also show Leia's career advancement incentives when not receiving housing or childcare subsidies.

${ }^{19}$ After EITC and CTC are taken into account, Leia actually receives a federal tax refund of $\$ 60,000$ from the government, compared to paying $\$ 31,000$ in federal income taxes as an RN (both values are over her lifetime in present-value terms).
} 


\section{Figure 7: Short-, Medium-, and Long-Term Net Public Returns to Advancement without Childcare or Housing Subsidy Assistance}

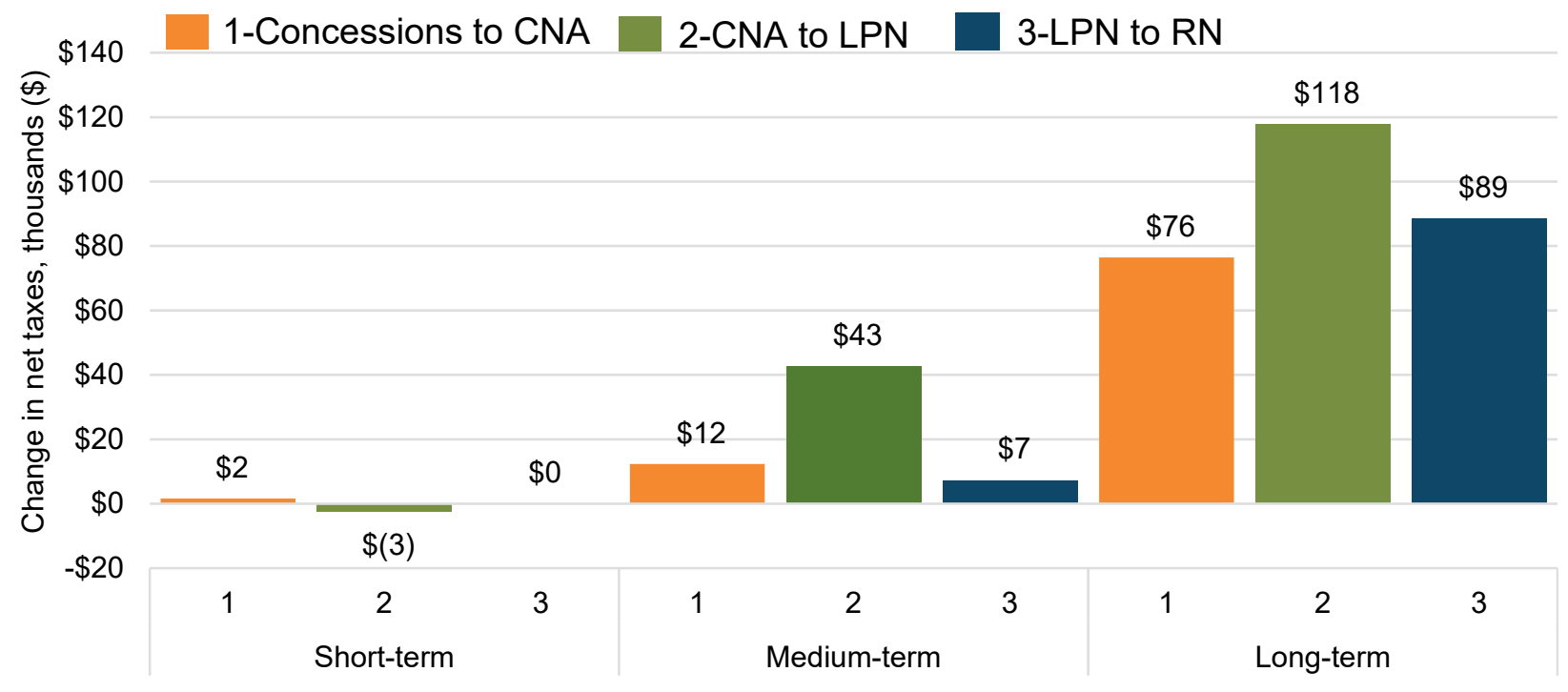

Notes: Short-term indicates ages 25 to 27 , medium-term ages 25 to 33, long-term ages 25 to the end of life. Figures are in present-value terms. Sums in text may not equal sum of numbers in chart due to rounding.

Sources: authors' calculations and The Fiscal Analyzer

\section{Policy Approaches to Mitigating the Benefits Cliffs Disincentives: Applications}

The foregoing analysis illustrates how benefits cliffs might discourage investments in skill acquisition that promote career advancement, despite substantial long-term gains to both individuals and the public. A key policy challenge is how to improve the short- to medium-run trade-offs for individuals along a chosen career pathway.

Scholars, policymakers, and practitioners have long recognized that benefits cliffs can be a barrier to the working poor. As such, a variety of policy solutions have been proposed. For example, the National Conference of State Legislatures (National Conference of State Legislatures 2019) and Circles USA (2018) provide recent reviews of actions policymakers are taking to address benefits cliffs. ${ }^{20}$ Shortterm solutions identified in the reports include funding a gradual phaseout of benefits rather than a sudden loss, raising eligibility limits so individuals can remain on benefits for a longer period of time, and providing monetary incentives for continued employment. Longer-term solutions include increasing availability of supportive services for individuals enrolled in education and training, expanding access to educational funding, and designing employer-funded programs that invest in the skills development of

\footnotetext{
${ }^{20}$ The NCSL report builds on a nationwide policy scan conducted by a group of six northeastern states.
} 
entry-level workers (National Conference of State Legislatures 2019, page 3). We refer readers to these reviews to read more about these proposals and others.

Our methodology allows policymakers to visualize how proposed solutions to benefits cliffs will affect low-income workers as they advance up a career pathway. In this section, we demonstrate how the methodology can be used to illustrate the holistic effect of a change in policy. By holistic, we mean that it takes into account access to multiple public benefits programs and/or factors that change with the passage of time as well as the short- and long-term financial gains of different career choices. We illustrate the methodology with two examples based on real programs under way in Florida and Mississippi. We then discuss two additional ways our methodology can assist service providers that offer either financial or career counseling to clients.

\section{Application 1: Families' ascent to economic security}

Families' Ascent to Economic Security (FATES) is a program targeted to parents who are at or near the childcare subsidy benefits cliff in Florida. The goal of FATES is to phase out the childcare subsidy gradually after parents enroll in education and training, obtain an occupation with a higher salary, and cross the childcare subsidy eligibility threshold. The program is currently operating as a small pilot study in Florida, supported by grants from the W.K. Kellogg Foundation, the Kresge Foundation, and the Morgridge Family Foundation as well as a combination of federal, state, and local social service funds. We use the methodology to show how the program's phaseout of the childcare subsidy affects Leia's incentive to advance up the health care career pathway.

The FATES program staff provided us with details for a proposed phaseout subsidy pilot in Orange County, Florida. Under the status quo, parents lose 100 percent of the childcare subsidy when their earnings cross 85 percent of state median income. The FATES model enables participants who would otherwise lose the childcare subsidy instead to pay 50 percent of the childcare costs in the first year following the loss of the subsidy, 75 percent of the childcare costs in the second year, and 100 percent from the third year on to any additional years of childcare.

In Figure 8, we repeat the net resources analysis in Figure 4, but we include the FATES childcare phaseout subsidy (dotted blue line). We also assume that Leia now lives in Orlando, Florida, which is the location of the proposed pilot. ${ }^{21}$ Upon entering employment as an $\mathrm{RN}$, she receives a substantial $\$ 36,000$ increase in annual income. Thus, Leia loses childcare when she graduates from school and becomes an RN. The solid blue line shows her net resources on the RN path without the phaseout subsidy. Despite earning more money as an RN, Leia's net resources decline upon graduation (from $\$ 13,500$ at age 29 to $\$ 11,300$ at age 30 ) due to loss of multiple public benefits.

\footnotetext{
${ }^{21}$ Switching the location to Orlando changes our calculation for the Section 8 housing subsidy. The cost of housing and the area median income are both higher in Miami compared to Orlando. Both of these factors will affect the implied value of the subsidy and the income threshold for eligibility.
} 
Figure 8: Annual Net Resources over Time, with FATES Phaseout Subsidy

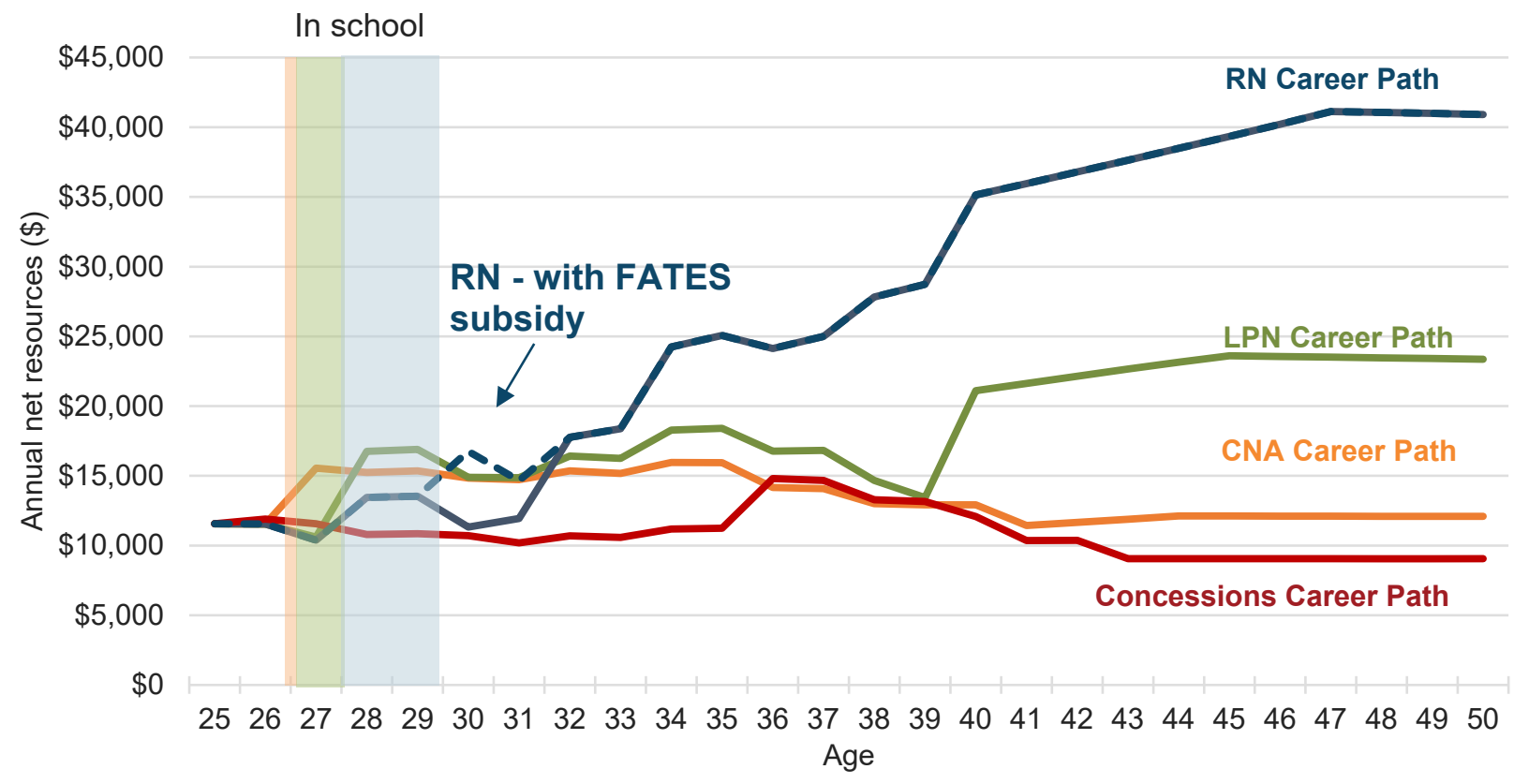

Sources: authors' calculations and The Fiscal Analyzer. All values are in current-year dollars.

With the FATES phaseout subsidy, the incentives change. The FATES phaseout smooths the benefits cliffs Leia would experience when she turns 30. Instead of declining, her net resources increase by about $\$ 3,200$ at age 30 . They decrease about $\$ 2,100$ at age 31 (remaining above the alternative noFATES scenario). After these two years, the FATES subsidy ends and Leia's net resources as an RN equal the net resources without a FATES phaseout subsidy. Further, without the FATES subsidy her net resources fall below those of the CNA path for ages 30 and 31. The FATES phaseout eliminates the discouraging result that Leia would be worse off as an RN than as a CNA when she begins employment as an RN at age 30 .

\section{Application 2: The Continuum of Services Model and asset mapping}

We can also use our methodology to simulate policy responses to the benefits cliffs and align supportive services to fill gaps in net resources that may discourage career advancement. One application of this approach is the Continuum of Services Model (CSM), developed in the state of Mississippi in collaboration with the U.S. Department of Health and Human Services Administration for Children and Families Region 4, the U.S. Department of Labor Employment and Training Administration, and the U.S. Department of Agriculture Food and Nutrition Service. The goal of CSM is to expand the 
access and alignment of wraparound supports available from the time of benefits application to skills assessment to employment and through a follow-up period. ${ }^{22}$

We first illustrate how the CSM uses transitional benefits to mitigate benefits cliffs as a barrier to employment. The CSM is designed to support low-income families as they transition off of TANF and into employment. Families who receive TANF basic cash assistance are also eligible to receive childcare assistance through the program. Upon entering employment, the loss of TANF could result in large cliff effects if the family has access to childcare through TANF and is unable to obtain Child Care and Development Fund (CCDF) subsidies. To help mitigate these cliff effects, some states provide transitional supports for families who lose eligibility for public benefits (see Circles USA review, 2018). States can use transitional TANF supports to expand payments for childcare support beyond the point at which families lose eligibility for TANF basic cash assistance. These transitional supports provide an important financial cushion as families enter employment.

The state of Mississippi has expanded transitional TANF supports to help families as they enter employment. Before the client loses TANF basic cash assistance benefits, caseworkers schedule a TANF transitional services appointment in which they arrange transitional benefits and discuss services available through the SNAP Employment \& Training (E\&T) program. ${ }^{23}$ The transitional benefits cover the full cost of childcare for 24 months and provide up to a $\$ 300$ per month reimbursement for transportation for 18 months.

In Figure 9, we apply our methodology to show how these transitional TANF supports would help someone like Leia afford childcare while in school. For this analysis, we modify the career pathway scenario shown in Figure 2. We assume that Leia skips the LPN step of the career pathway and goes directly from the CNA to the RN; this alternative career path allows transitional TANF childcare to support Leia for the two-year period she is enrolled in school. It also allows Leia to advance more quickly into a high-paying occupation in the health care sector. We also simplify the net resources calculation to better illustrate the impact of transitional TANF. Instead of including all the benefits for which Leia is eligible, we assume she receives only TANF-related benefits. She also receives tax credits through the EITC and CTC. In this scenario, she pays two additional costs: the cost of school, which is $\$ 5,664$ per year for two years for tuition and fees, and the cost of transportation, which is $\$ 300$ per month. ${ }^{24}$

We assume the parent lives in Jackson, Mississippi. At age 26, she is unemployed but receiving TANF cash assistance and childcare assistance through TANF. ${ }^{25}$ The next year, at age 27, she obtains a part-time job as a CNA and enrolls in school to become an RN. During this year, the earnings from her job as a CNA cause her to lose TANF cash assistance eligibility, and she begins to pay for school. Under the assumption of no transitional TANF (which if received, would allow her to keep childcare assistance)

22 We received details about the CSM in personal correspondence from officials at the Mississippi Department of Human Services, the Administration for Children and Families Region 4, and the Food and Nutrition Service.

${ }^{23}$ Details of the transitional TANF program were received via email correspondence with Mississippi state human services officials.

${ }^{24}$ We assume transportation costs equal the maximum value of the monthly transportation reimbursement.

${ }^{25}$ We assume she is meeting the work requirement of the TANF program. 
her net resources increase by approximately $\$ 3,200$ at age 27 . Thus, her employment income combined with over $\$ 5,000$ in tax credits just barely offset the combined loss of TANF, childcare assistance, and the additional expense of school.

Over the two years when she is either unemployed or in school and working part-time, Leia's net resources are below the financial break-even point of zero-she does not have sufficient resources (income and benefits) to pay basic expenses. The negative financial resources, illustrated in Figure 9, result from the particular assumptions of this example: we assume Leia only receives a limited set of public benefits to help her meet her expenses (childcare, health insurance, housing, food, and transportation). To have sufficient financial resources, low-income workers like Leia would need to access additional supports (such as Medicaid, the ACA subsidy, and housing assistance), obtain financial assistance (such as other grants, loans, or lines of credit), ask family for assistance, or reduce their expenses in a way that does not lead to food insecurity or inadequate childcare, health care, or housing.

The dotted purple line in Figure 9 plots net resources when the parent receives transitional TANF supports. The shaded purple column indicates the 24-month transitional TANF period in which she is eligible for childcare assistance. Upon enrolling in school and obtaining a part-time job, she is immediately rewarded; her net resources increase by approximately $\$ 10,700$ between ages 26 and 27 . Further, compared to no transitional TANF scenario, her net resources are approximately $\$ 7,500$ higher. Thus, the transitional TANF provides financial support as well as a financial incentive to enroll in school and start working. At age 29, she graduates and begins work as a full-time RN. Her income increases substantially. At this time transitional TANF ends and she loses childcare assistance and the transportation stipend. Despite these losses, her net resources increase to $\$ 13,700$. At this level of income, she is able to afford all of the expenses that we include-housing, childcare, food, health insurance, and transportation. She has reached self-sufficiency, which is an overarching goal of the Mississippi program. 


\section{Figure 9: Transitional TANF Supports}

\section{Net Resources for the Direct RN Pathway, with and without Transitional TANF Supports Dollars, Annual}

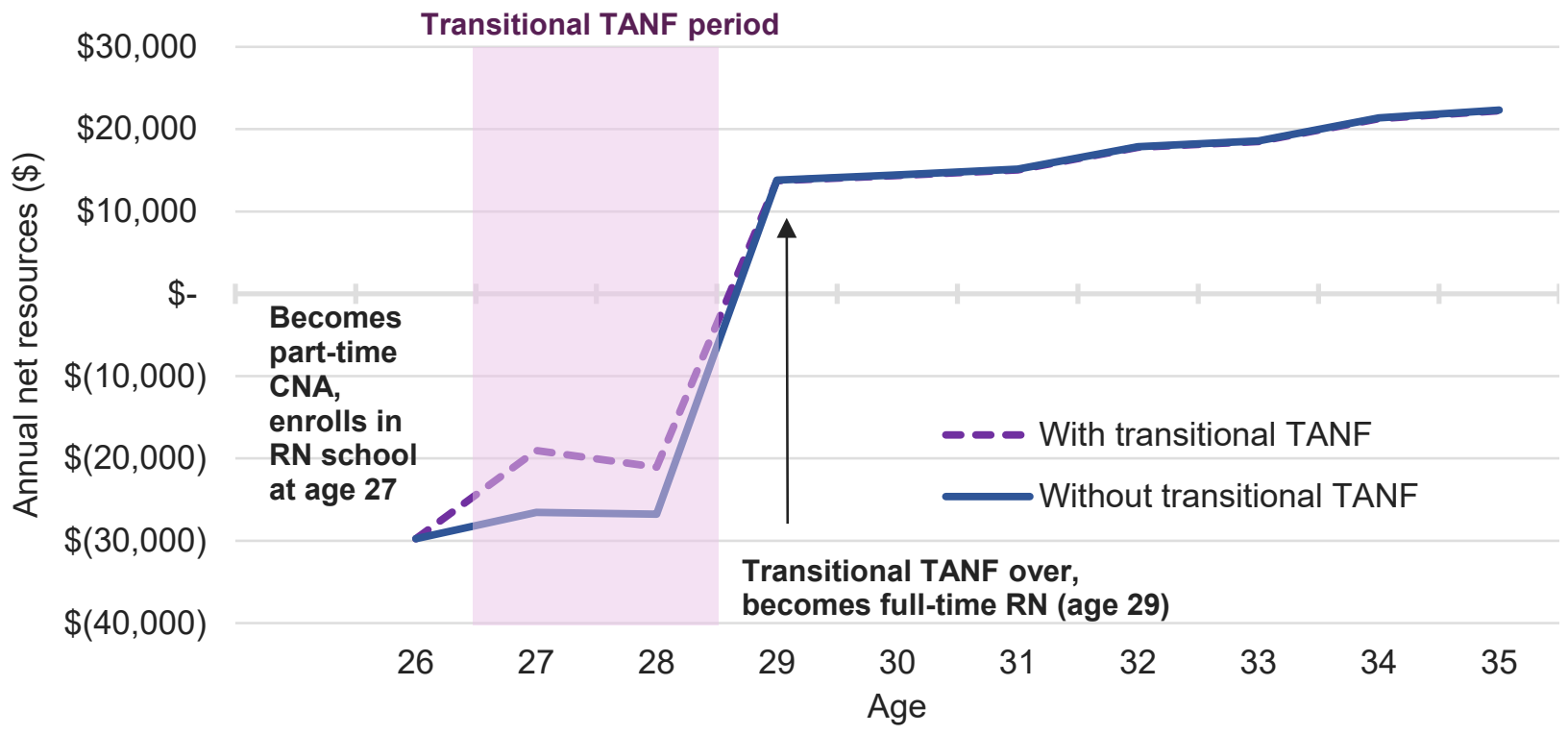

Notes: Net resources only include tax credits, TANF, and transitional TANF for the benefits amount. We assume the single mother of two children lives in Jackson, Mississippi. Values below zero are in parentheses and indicate negative net financial resources. All values are in current-year dollars.

Sources: authors' calculations and The Fiscal Analyzer

Transitional TANF is only one component of the CSM; it also encourages caseworkers to apply resources from other programs to provide additional support for low-income families. A key feature of the CSM is asset mapping, in which policymakers identify multiprogram, multipartner resources available through TANF, SNAP, SNAP Employment and Training (SNAP E\&T), and WIOA to support the client as she starts training and finds employment on a career pathway. Our methodology can help caseworkers and policymakers identify how and when to align these programs to improve the financial stability and career advancement incentives for any client.

Figure 10 repeats the analysis in Figure 9, but includes additional funding that could be provided. We assume the client receives SNAP between ages 26 and 28 and SNAP E\&T and WIOA training funds while in school (ages 27 and 28). The annotations demonstrate how a caseworker could use our methodology to identify when the multiprogram, multipartner resources would be available to the client. We highlight three points. First, at age 27, when Leia obtains a part-time job, she loses TANF basic assistance eligibility, but becomes eligible for transitional TANF (which includes childcare and transportation subsidies). At this time she maintains SNAP funds while also qualifying for SNAP E\&T services. SNAP E\&T partners with select community colleges in the state to provide subsidies for 
textbooks, fees, and certifications. In this example, the value of SNAP E\&T is estimated at $\$ 1,428$ per year. Further, WIOA funds help to cover most of her tuition and fees $(\$ 6,000$ over two years $) .{ }^{26}$ In contrast to Figure 9, where she pays the cost of school, her net school cost in this scenario is under $\$ 1,000$ per year. ${ }^{27}$ Like in Figure 9, at age 29 she begins work as a full-time RN with considerably higher net resources and is self-sufficient. ${ }^{28}$

\section{Figure 10: Asset Mapping}

\section{Net Resources for the Direct RN Pathway, with and without Transitional TANF Supports, SNAP E\&T, and WIOA Dollars, Annual}

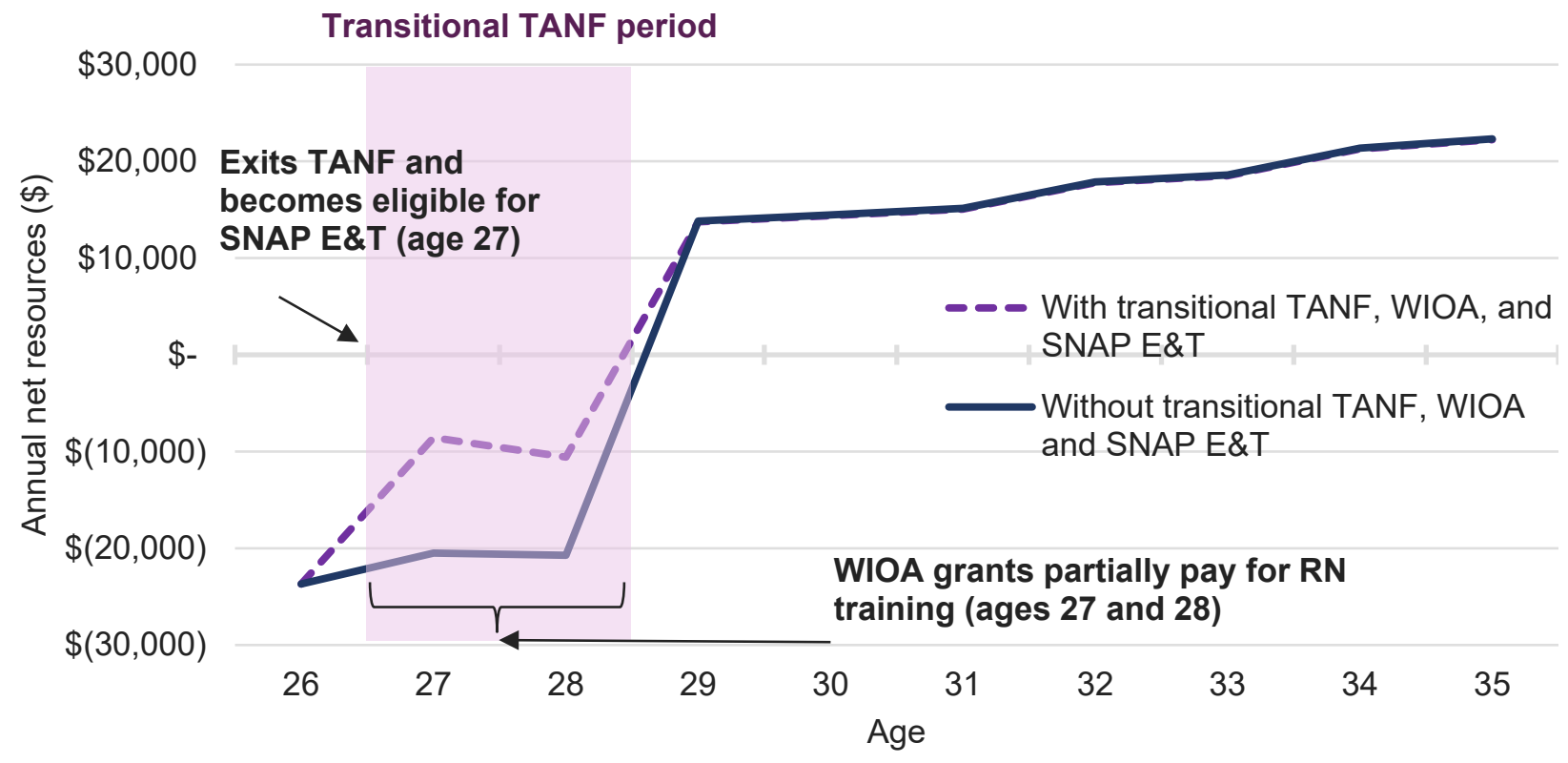

Notes: Net resources only includes tax credits, WIOA training grants, SNAP, SNAP E\&T, TANF, and transitional TANF for the benefits. The inclusion of SNAP moves the blue line higher relative to Figure 9. The inclusion of WIOA and SNAP E\&T will move the purple dotted line higher relative to Figure 9. We assume the single mother of two children lives in Jackson, Mississippi. Values below zero are in parentheses and indicate negative net financial resources. All values are in current-year dollars.

Sources: authors' calculations and The Fiscal Analyzer

\footnotetext{
${ }^{26}$ As in Figure 9, we assume the total cost of tuition and fees for a two-year RN degree is $\$ 11,328$ and that transportation expenses are $\$ 300 /$ month.

${ }^{27}$ We obtained details about RN tuition, fees, and WIOA training funds from the Mississippi Eligible Training Provider List, available at mdes.ms.gov/i-need-a-job/job-searching-resources/training-education/eligible-trainingprovider-list-etpl-system/.

${ }^{28}$ Caseworkers could draw on additional resources to support the career transition. For example, an individual using WIOA funds to pay for RN training likely is eligible to receive WIOA supportive services funding that would help him or her pay for expenses such as childcare or transportation.
} 
These examples highlight the significant financial challenge low-income workers with children face when returning to school to further their careers. As was the case in Figure 9, Figure 10 reveals that neither transitional supports nor transitional supports plus WIOA and SNAP E\&T provide sufficient financial resources to allow Leia to meet her basic expenses prior to completing her RN training. However, the asset mapping approach shows considerable promise in mitigating the need for additional support-the self-sufficiency deficit in Figure 10 is half of that in Figure 9. More broadly, as noted, this example again illustrates how our methodology can be deployed to analyze the asset-mapping model and identify where further supports may be needed to support lower-income individuals making the human capital investments that can transition them to self-sufficiency.

\section{Financial predictability for low-income families}

The current system of federal and state work supports (benefits and taxes) is highly complex. Benefits amounts vary by household size, family earnings, state and local rules, and even caseworker discretion; taxes also vary by location (Romich, Simmerlink, and Holt 2007). The results of this complex system are that benefits cliffs (or, more generally, marginal tax rates) are hard to predict for even experts. Romich (2006) reports that low-income families have limited awareness of these issues, mainly due to complex program design. Families may only learn about decreases in net family resources after they experience them. The results from this unanticipated loss, as Romich (2006) writes, are "frustration," "disbelief," and a sense of being "persecuted for getting a raise." ${ }^{29}$ Planning and appropriate financial counseling could reduce the negative emotional reactions reported in Romich (2006), when individuals experience the surprise revelation that a higher-paying job does not always lead to a higher standard of living in the near term. Financial forecasts can help low-income families plan for and manage changes in net family resources, which is preferable to trying to "untangle benefit decreases and reduced incomes" after a loss in benefits has occurred (Romich, Simmerlink, and Holt 2007).

As discussed in the introduction, the methodology used in this paper has been turned into a tool called CLIFF (Career Ladder Identifier and Financial Forecaster). CLIFF allows users to customize career paths and visualize their specific benefits cliffs, tax increases, income growth, and temporary drops in income due to training enrollment.

Caseworkers and career counselors can use CLIFF to target and efficiently use work supports. The calculations will reveal the net resources an individual loses when he or she enrolls in training (and shifts to part-time work or stops working altogether) or loses public benefits (due to a raise, an increase in hours, or a job change). In each of these scenarios, the individual may experience a large financial shock or even lack the resources needed to meet basic expenses. CLIFF will quantify the magnitude of this loss in income as well as any changes in public benefits receipt.

\footnotetext{
${ }^{29}$ Indeed, when doing research on these benefits programs in order to conduct the analysis for this paper, we were not able to rely only on government websites. Instead, we had to dig through legal documentation and call government agencies directly.
} 
Another way CLIFF will help target financial supports is to show when these cliffs may appear in a future period after initial employment. Traditionally, organizations use supportive services during training enrollment through entry-level employment; fewer resources are devoted to supportive services after employment (though there are exceptions). However, due to a rise in income and subsequent loss in public benefits, an individual may require supportive services or extra financial support even months or years after securing employment. The loss can occur immediately after employment and the associated earnings increase, or after a longer time period once earnings growth or changes in family composition moves the individual over an eligibility threshold.

Training providers and other nonprofits can target supportive services and additional financial resources to these post-employment cliffs in at least two ways. Supportive services can help alleviate any short-term financial shortfalls while in training to help incentivize individuals to train for career advancement. As we discussed in the Leia example, an individual may be financially worse off in the short term as an RN than as an entry-level CNA. Supportive services can help the individual reduce the cost of some basic expenses after completing the more advanced training, ensuring that the individual is still financially better off with the advanced degree and preserving the economic incentive to seek training. Over the long term, larger pools of financial resources can be used to phase out the loss of particularly large cliffs such as childcare subsidies and reduce high marginal tax rates due to the combined impact of tax payments and benefits loss. ${ }^{30}$

\section{Informed training choice}

From the perspective of human capital theory, information-knowledge of the cost, benefits, risk, and opportunities - plays a key role in educational choice. ${ }^{31}$ Through its emphasis on providing customers with information on the economic returns to different training programs, WIOA assumes an individual uses labor market information about different careers and makes training choices in a rational way. Signed into law in 2014, WIOA seeks to "ensure the informed choice of participants among training services providers" (Sec. 122). By incorporating the loss of benefits and earnings growth related to experience, CLIFF provides a more complete assessment of the financial returns to training so individuals can make more informed decisions about training programs and career advancement.

The methodology we develop in this paper adds to existing approaches to inform labor market decisions by providing labor market information and benefits cliff calculations in several ways. First, there are several benefits cliffs calculators readily available that demonstrate the trade-off between

\footnotetext{
30 See Wood et al. (2018) for a discussion of a pilot cliff smoothing program in Colorado. Our above analysis of the FATES program shows exactly how phaseout programs can increase the financial incentive for career advancement.

${ }^{31}$ There is extensive academic research on the labor market information and educational choice (Wiswall and Zafar 2015; Baker et al. 2018; Ruder and Van Noy 2017; Jensen 2010; Hastings, Neilson, and Zimmerman 2015).
} 
income and public benefits receipt for particular household types, but they model static scenarios. ${ }^{32}$ These existing tools do not take into account the passage of time to include things like changes in family structure (such as aging of children) nor do they demonstrate career-specific wages or wage growth in a career pathways framework. In addition, typical presentations of labor market outcomes such as the median wages of different careers fail to account for the impact of taxes, the loss of public benefits as individuals begin to earn more than the benefit income eligibility thresholds allow, or a comparison of short- versus long-term earnings.

In contrast to existing benefits cliffs calculators, CLIFF compares occupation-specific choices over time. CLIFF also allows career counselors to design a career pathway for clients and to include factors required to advance up a career pathway, such as the cost of schooling and the time it takes to complete the credential. This type of career planning tool could be used by career counselors in job centers, by caseworkers, career, and technical education teachers and counselors in secondary schools, and by students in colleges and universities.

\section{Conclusion}

This discussion paper investigates an apparent barrier to career advancement-benefits cliffs, or the loss of critical financial resources over time due to income exceeding eligibility limits for public benefit programs. Indeed, low-income workers, particularly those with children, may face significant financial disincentives to progress to a higher-paying job.

The current design of the benefit and tax system creates a complex and ever-changing set of financial incentives as our hypothetical single mother advances along the health care services pathway. She is financially worse off in the short term if she acquires credentials to become a higher-paying LPN. She is financially worse off in the medium term if she advances from an LPN to a higher-paying RN. These losses of financial resources provide little short-term financial incentive to move beyond an entrylevel CNA position. While the choice to stay as a CNA may seem reasonable from a short-term perspective, there are large long-term gains for both Leia and the public. When Leia does not complete the career path from a CNA to an RN, she has $\$ 144,000$ less in net resources over her lifetime and the taxpayer forgoes $\$ 309,000$ in potential net public savings, measured in present value.

Our choice to analyze the case of one hypothetical single mother has strengths and limitations. The strength of this case study approach is that we provide detailed analysis of the financial incentives for Leia to advance up the career pathway and are able to generate a concrete, relatable example. The limitation is generalizability to other individuals and localities. While benefits cliffs as barriers to career advancement exist in many industry sectors and for many different types of individuals, our results only apply to the specific case of Leia, a single mother with two children who lives in Miami-Dade County and receives a specific portfolio of public benefits and tax credits. Furthermore, in our hypothetical example,

\footnotetext{
${ }^{32}$ For examples, see the Economic Stability Indicator (www.economicstabilityindicatormn.org) designed for families living in Minnesota; the Net Income Change Calculator (http://nicc.urban.org/netincomecalculator/), built for all states, but based on 2016 laws; and the Family Resource Simulator (www.nccp.org/tools/frs) from the National Center for Children in Poverty.
} 
Leia is eligible for and receives all of the listed public benefits and tax credits, except for the supplementary analysis in which we exclude housing and childcare subsidies. In practice, not all eligible individuals receive benefits or tax credits due to factors such as demand exceeding availability (such as housing vouchers and childcare assistance) and difficulties applying and determining eligibility. ${ }^{33}$ The intent of our case is to illustrate how the loss of public benefits can impede career advancement.

Ongoing and future work on this project will continue in several directions. We are modeling career choice on other career pathways, such as information technology. We also are analyzing different geographic locations and family profiles, in which we vary age, benefits receipt, and career pathways. The goal of this analysis is to estimate the career advancement incentives of a broader range of lowincome individuals than the select case presented in this paper. In addition, future work will incorporate administrative data on public benefit receipt to examine the prevalence and magnitude of these disincentives on the population of low-income individuals who are seeking career-advancing workforce development services.

\footnotetext{
${ }^{33}$ Chien and Macartney (2019) use the Current Population Survey and the TRIM3 microsimulation model to estimate the 10 most common public benefits program combinations. Relatively few families, for example, receive housing subsidies in combination with other public benefits programs.
} 


\section{Appendix}

\section{Wage assumptions}

For simplicity of interpreting career paths over the lifetime, we assume price levels grow at the same rate of wages. We assume the worker being modeled here-Leia-works 40 hours a week if not in school, and 20 hours a week while in school. We assume that income for each career varies by state and years of experience. Wage data from each occupation come from the U.S. Bureau of Labor Statistics State Occupational Employment and Wage Estimates, and are shown in appendix Table $1 .{ }^{34}$ For all jobs, we assume the starting wage is equal to the 25th percentile in the state of Florida and the wage increases with each year of experience, maxing out at the 75th percentile after 17 years of experience. We assume flat wage growth after 17 years. ${ }^{35}$

\begin{tabular}{|l|l|l|l|}
\hline \multicolumn{5}{|c|}{ Appendix Table 1: Hourly Wages and Wage Growth by Occupation (2018 data) } \\
\hline $\begin{array}{l}\text { Occupation and Standard Occupational } \\
\text { Classification code }\end{array}$ & $\begin{array}{l}\text { Starting } \\
\text { wage }\end{array}$ & $\begin{array}{l}\text { Ending wage } \\
\text { (after 17 years) }\end{array}$ & $\begin{array}{l}\text { Wage growth per } \\
\text { year (for 17 years) }\end{array}$ \\
\hline $\begin{array}{l}\text { "Concessions": Counter Attendants, Cafeteria, } \\
\text { Food Concession, and Coffee Shop (35-3022) }\end{array}$ & $\$ 8.92$ & $\$ 10.69$ & $1.07 \%$ \\
\hline "CNA": Nursing Assistants (31-1014) & $\$ 10.94$ & $\$ 14.48$ & $1.66 \%$ \\
\hline $\begin{array}{l}\text { "LPN": Licensed Practical and Licensed } \\
\text { Vocational Nurses (29-2061) }\end{array}$ & $\$ 18.42$ & $\$ 23.82$ & $1.52 \%$ \\
\hline "RN": Registered Nurses (29-1141) & $\$ 26.66$ & $\$ 36.74$ & $1.90 \%$ \\
\hline
\end{tabular}

Sources: authors' calculations and U.S. Bureau of Labor Statistics' Occupational Employment Statistics

\section{State versus federal net public savings}

We estimate that only a small portion of the gains at each step would be realized by the state. There are at least two reasons for this. First, the benefits programs that we assume Leia is enrolled in are mostly funded by the federal government (see Table 1 in the paper for details). Second, Florida does

\footnotetext{
${ }^{34}$ Available at www.bls.gov/oes/special.requests/oesm18st.zip.

${ }^{35}$ Wage growth tends to taper off after 15 to 20 years of experience. See Rubinstein and Weiss (2007). Further, we examined wage data by age from the American Community Survey, adjusted for wage level differences between the data sources to confirm the growth in wages tends along a similar path.
} 
not have a state income tax or state versions of the EITC and CTC. Appendix Figure 1 decomposes the net gains to federal and state government. ${ }^{36}$

\section{Appendix Figure 1: Lifetime Net Public Savings}

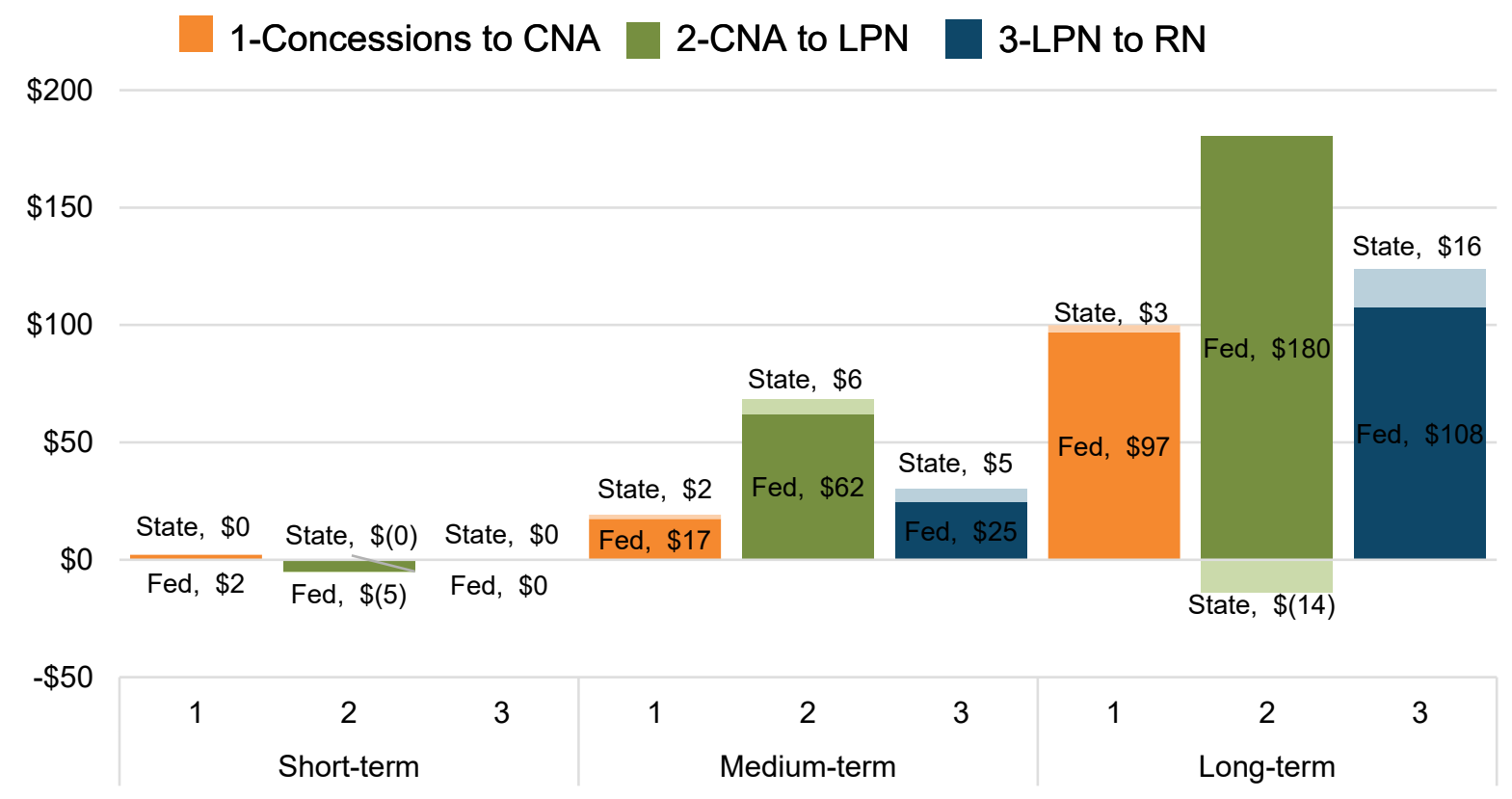

Note: Figures are in present-value terms.

Source: The Fiscal Analyzer

\section{Results without childcare and rental housing subsidies}

In appendix Figure 2, we remove the assumption that Leia receives the childcare and housing subsidies and then show Leia's annual net family resources by career path. As discussed in the main body of the paper, a large percentage of eligible families do not receive these benefits. Without the resulting benefits cliffs from losing these subsidies, Leia has a positive short-term incentive for career advancement. However, the losses in benefits and changes to taxes still create a complex set of financial incentives. At several points in each career path, net resources actually decrease. In addition, beginning at age 36, the net resources line for the CNA path decreases to be approximately equal to net resources for the concessions path. Thus, in the short term, Leia has an incentive to advance to a CNA from a concessions job, but starting at age 36 , those relative gains from career advancement diminish due to changes in benefits eligibility.

\footnotetext{
${ }^{36}$ Based on state of Florida budget documents, we assume 81 percent of the cost of childcare assistance is paid by the federal government and 29 percent is paid by the state.
} 


\section{Appendix Figure 2: Net Resources without Housing or Childcare Support}

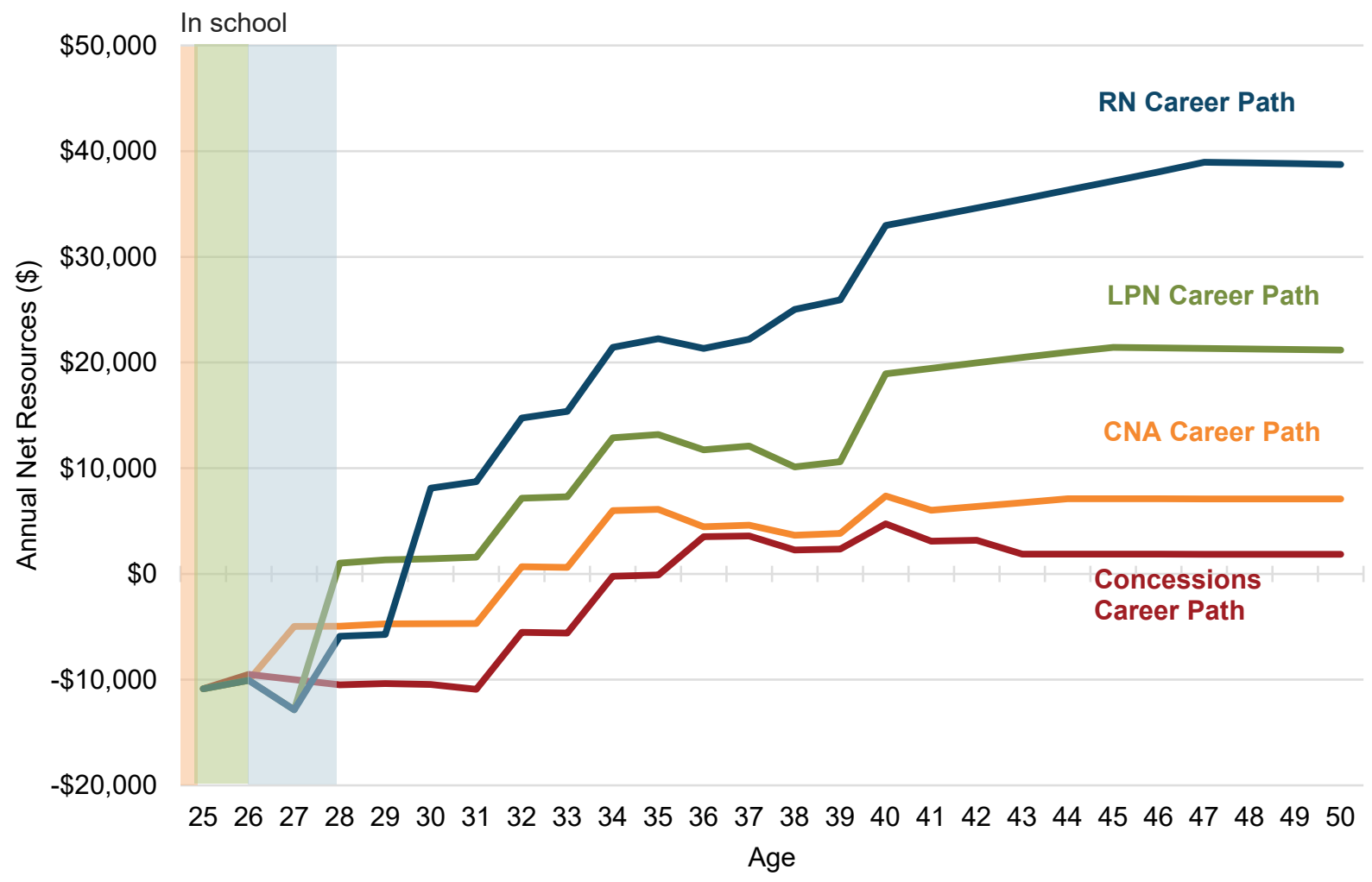

Notes: Shaded areas indicate a decrease in earnings at age 27 for the LPN line, and at ages 28 and 29 for the RN line, due to enrollment in fulltime training and a change to part-time work status. Note that taxes increase substantially at age 40 , when she no longer has dependents to claim.

Sources: authors' calculations and The Fiscal Analyzer

\section{Estimated value of public benefits and expenses by career path}

Figure 4 in the main body of the paper shows annual net resources over time and by career path. Over time, annual net resources change because the value of benefits, expenses, and taxes change, and these changes differ by career path. To illustrate these differences, we provide the estimated value of each benefit program, taxes, and expenses by age and career path in appendix Figures 3 through 14. Note that all values in these figures reflect current year dollars, and thus do not incorporate future inflation. In this figure, we follow the same career path definitions outlined in the main body of the paper: the concessions job for Leia's entire life (concessions career path); the concessions job to the CNA (CNA career path); the concessions job to the CNA to the LPN (LPN career path); and, finally, the full progression from the concessions job to the CNA to the LPN and to the RN (RN career path). 


\section{Appendix Figure 3: Public Benefits for Concessions Career Path}

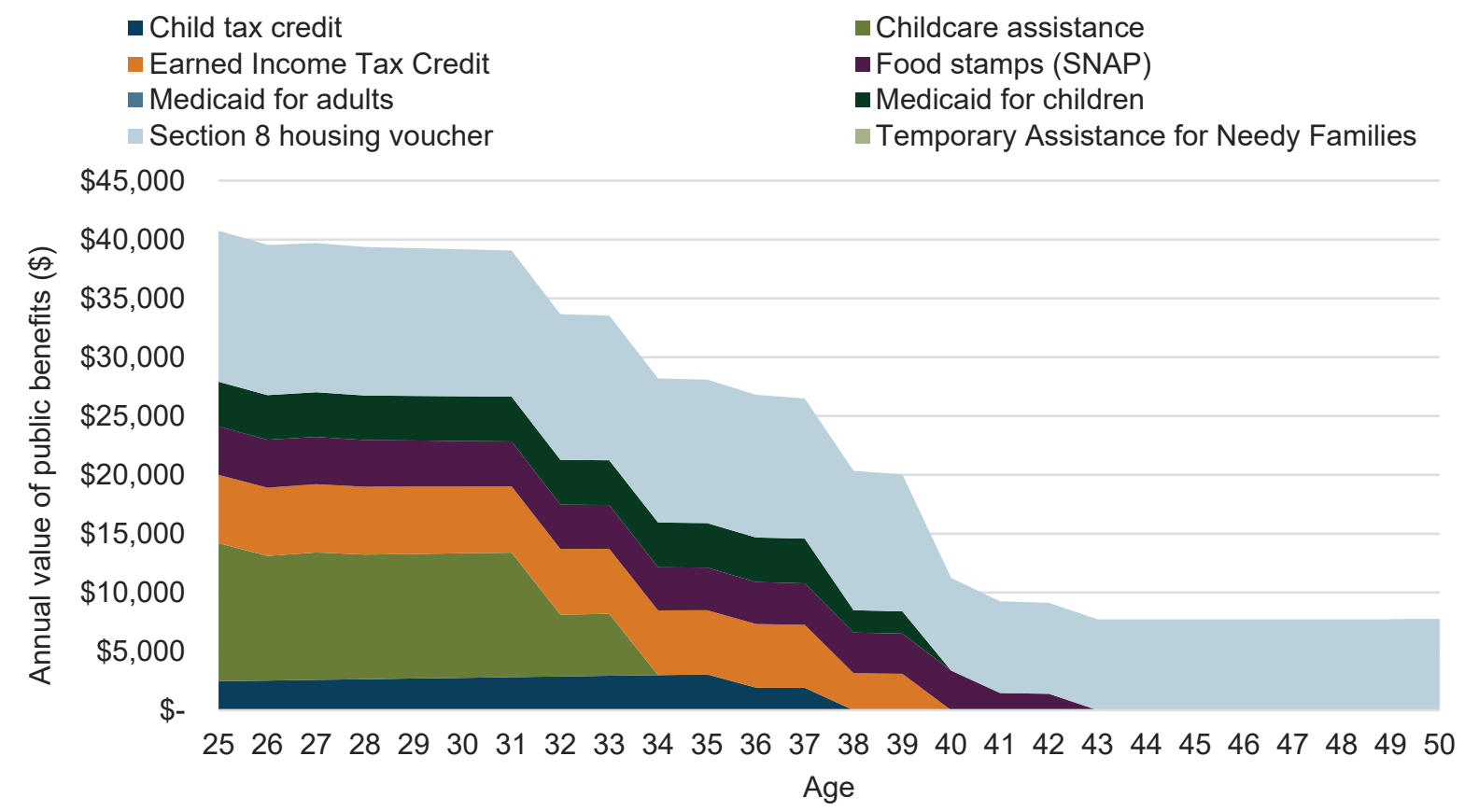

Sources: authors' calculations and The Fiscal Analyzer; some legend categories may not be shown on graph due to zero values 


\section{Appendix Figure 4: Public Benefits for CNA Career Path}

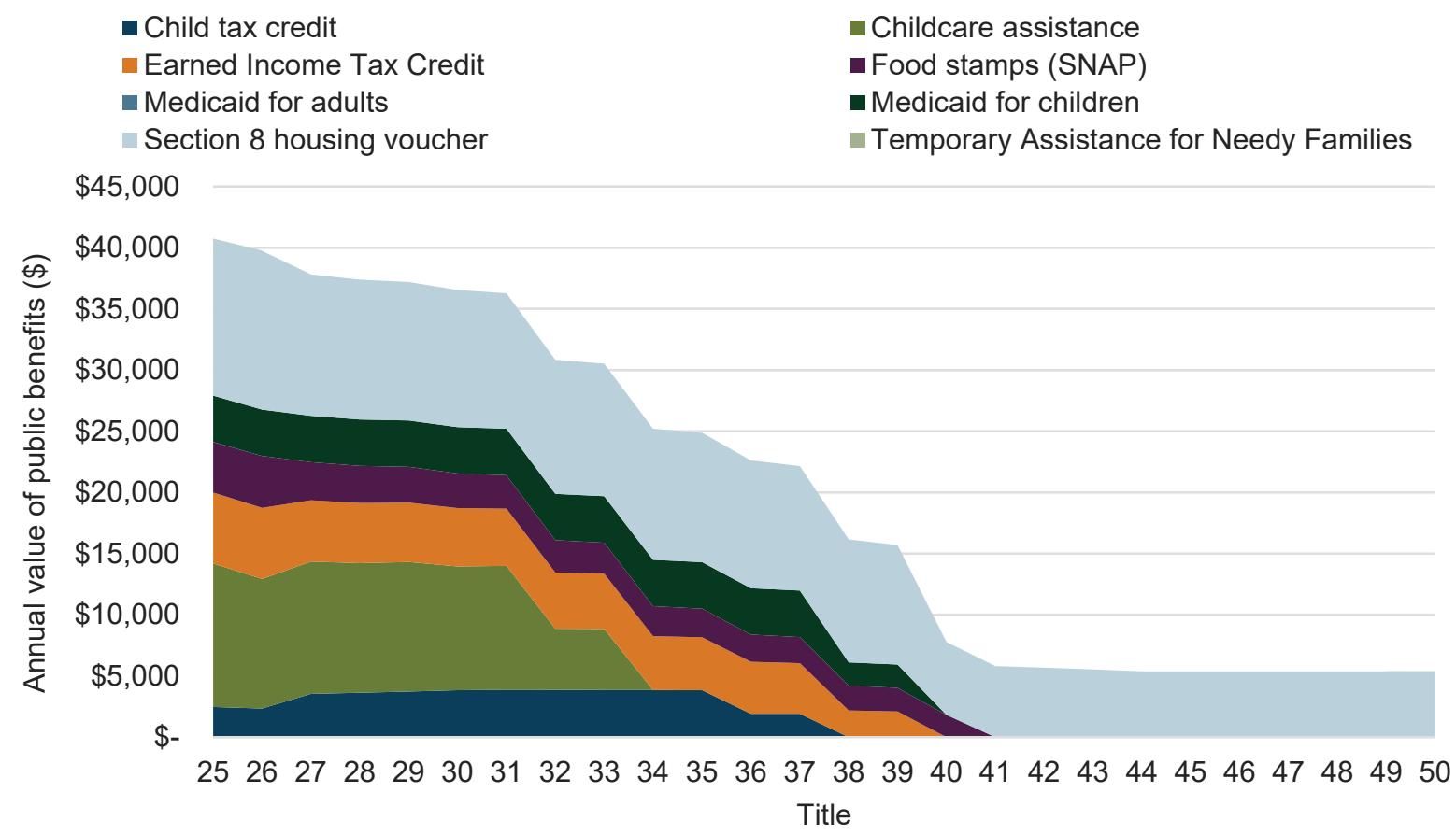

Sources: authors' calculations and The Fiscal Analyzer; some legend categories may not be shown on graph due to zero values

\section{Appendix Figure 5: Public Benefits for LPN Career Path}

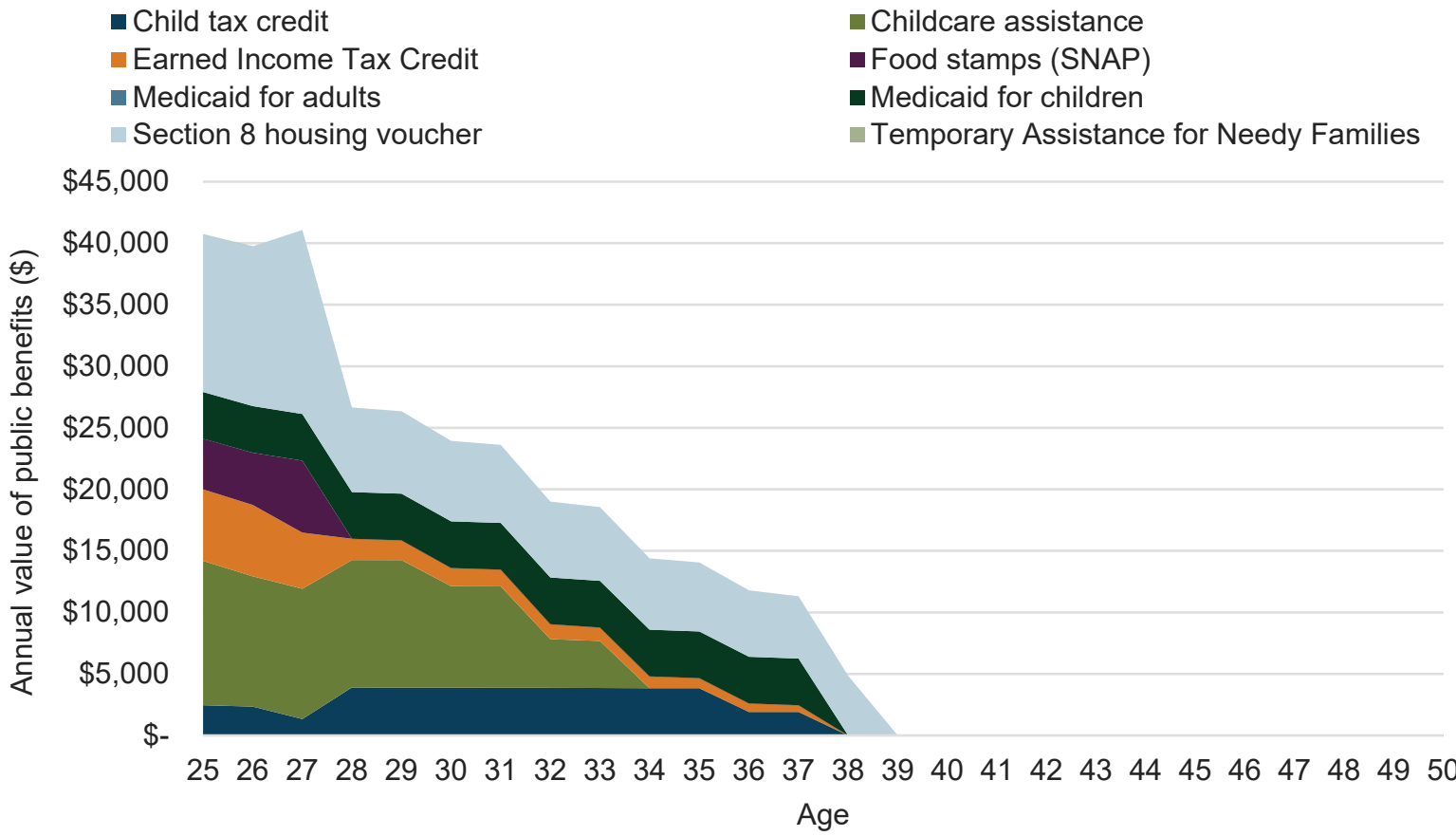

Sources: authors' calculations and The Fiscal Analyzer; some legend categories may not be shown on graph due to zero values 


\section{Appendix Figure 6: Public Benefits for RN Career Path}

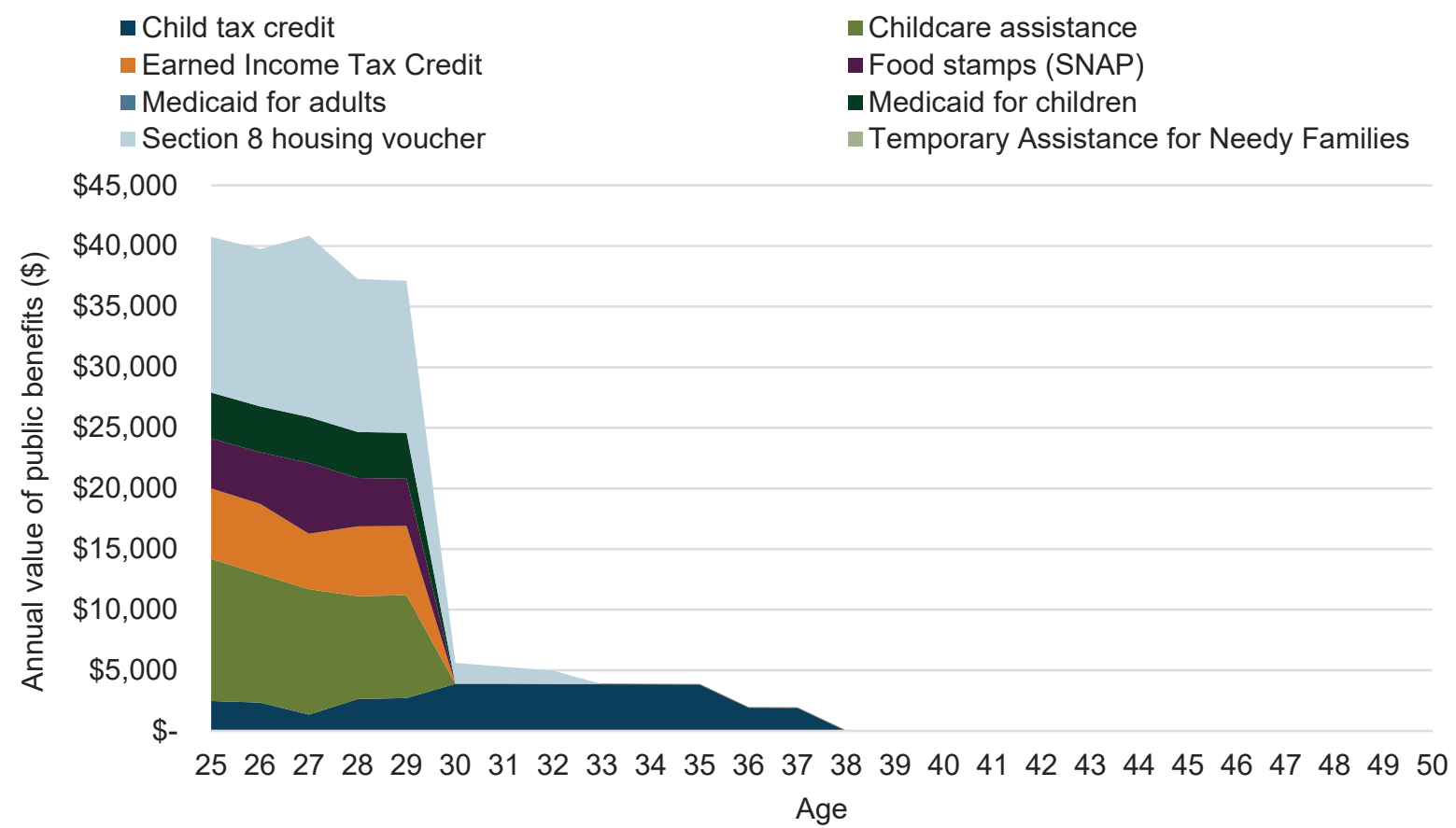

Sources: authors' calculations and The Fiscal Analyzer; some legend categories may not be shown on graph due to zero values 
Appendix Figures 7 through 10 show Leia's total expenses, by category, for each career path. Total expenses are pre-benefit amounts and thus are different from the net expenses shown in Figure 1.

\section{Appendix Figure 7: Expenses for Concessions Career Path}
- Childcare
- Food
- Housing
- Health care

$\$ 55,000$

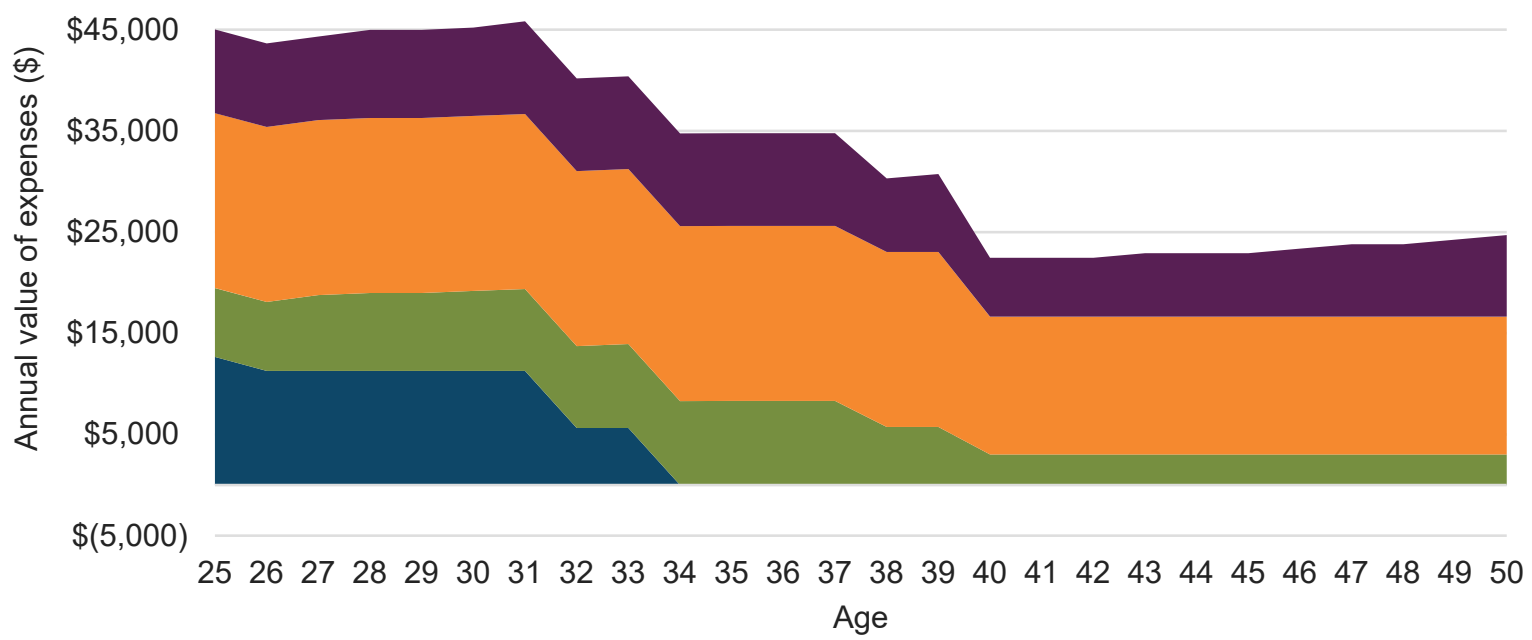

Sources: authors' calculations and The Fiscal Analyzer 


\section{Appendix Figure 8: Expenses for CNA Career Path}

- Childcare $\quad$ Food Housing $\quad$ Health care

$\$ 55,000$

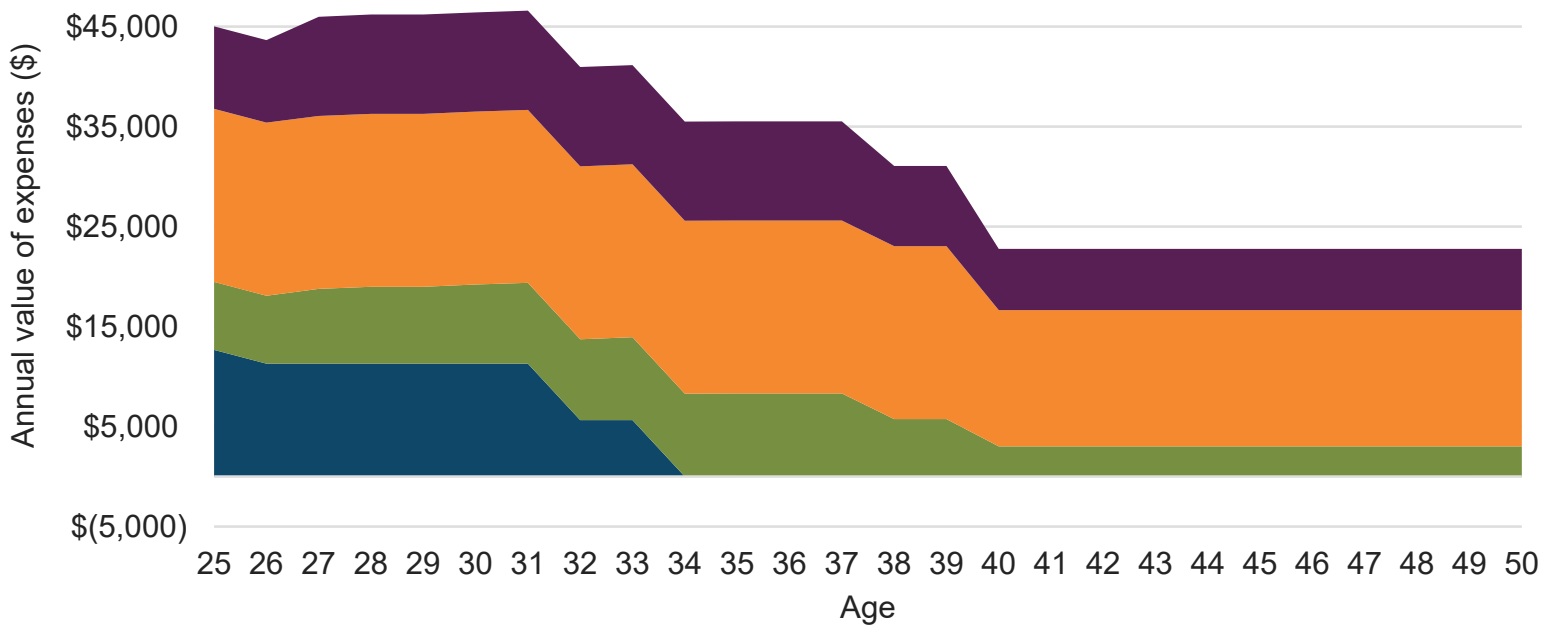

Sources: authors' calculations and The Fiscal Analyzer

\section{Appendix Figure 9: Expenses for LPN Career Path}

- Childcare $\quad$ Food Housing $\quad$ Health care

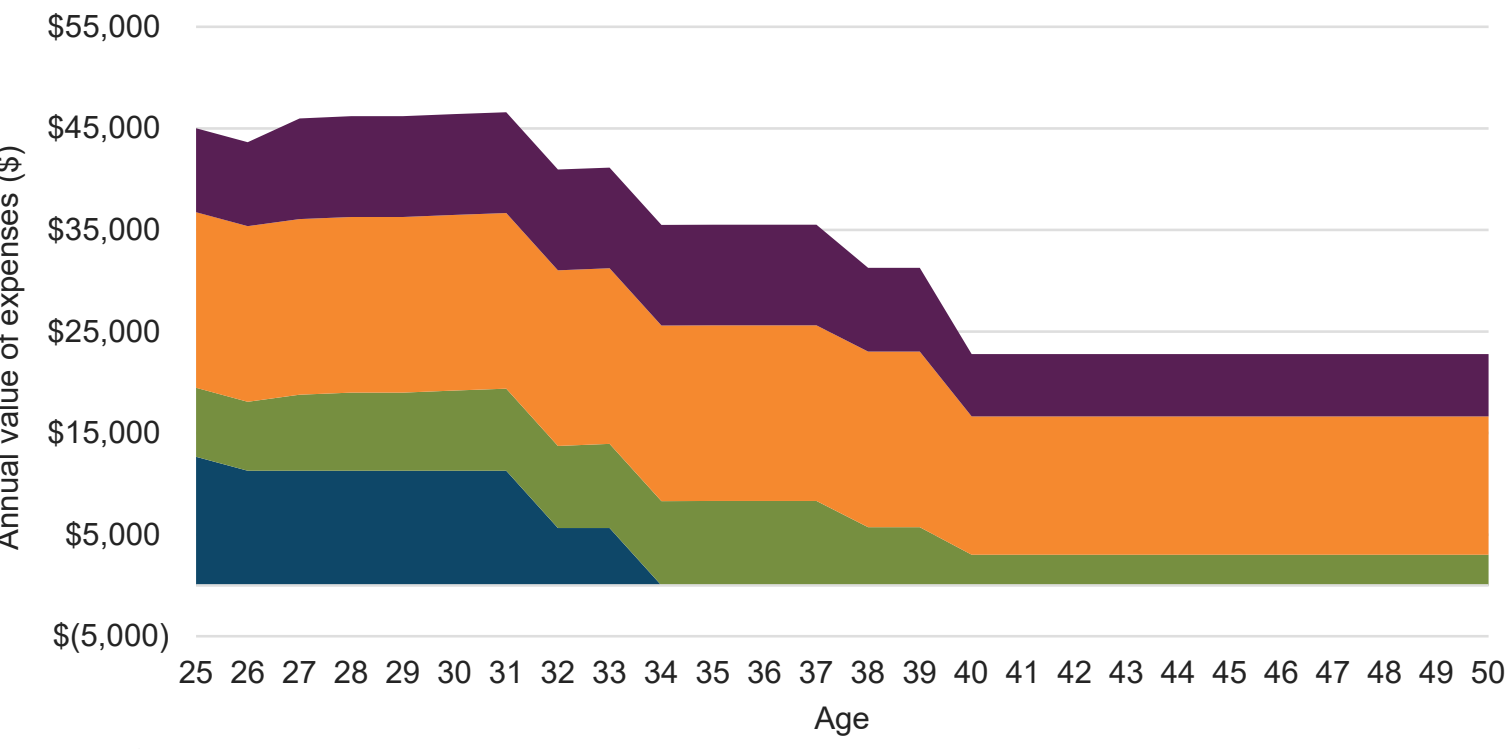

Sources: authors' calculations and The Fiscal Analyzer 


\section{Appendix Figure 10: Expenses for RN Career Path}

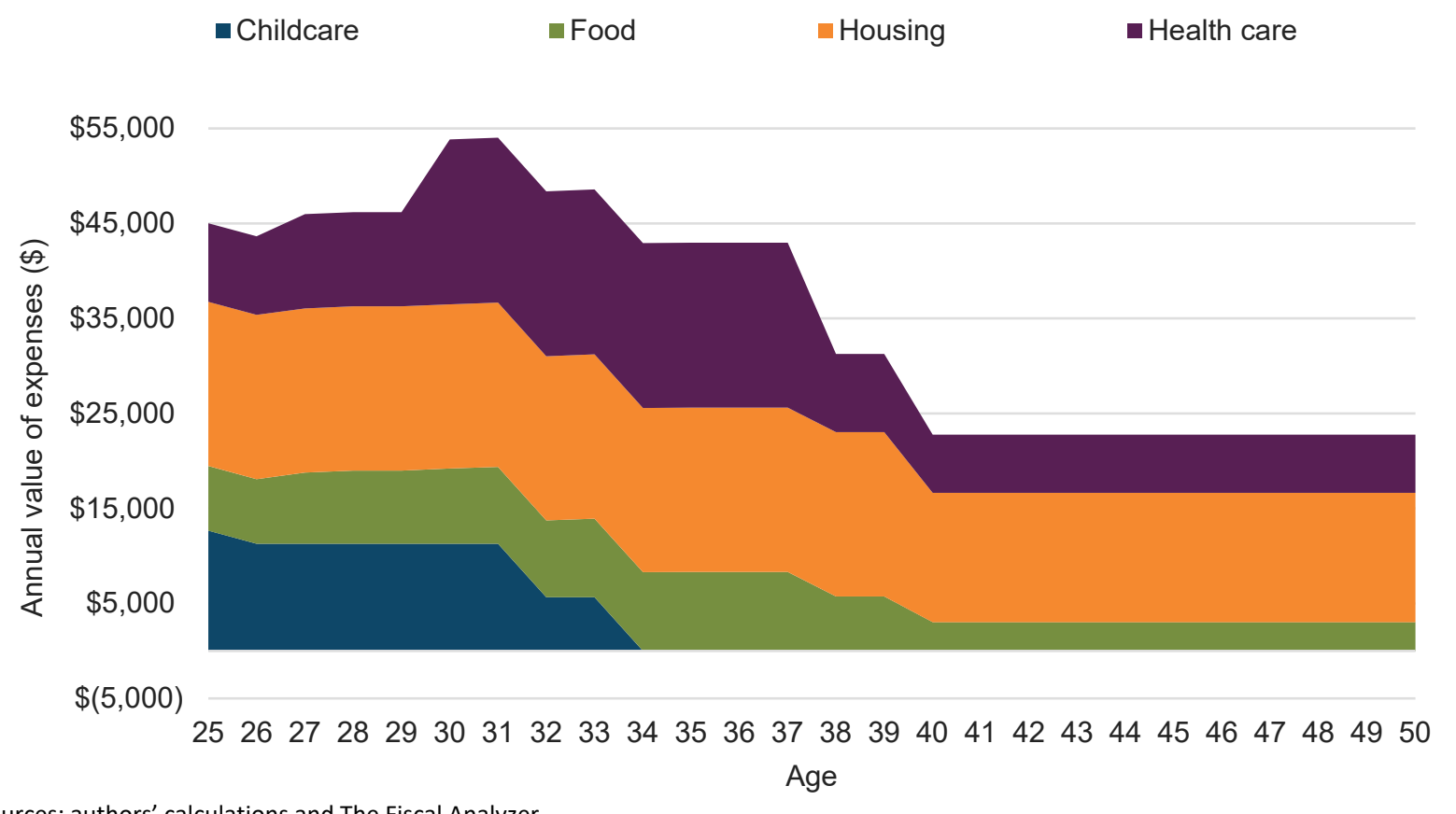

Sources: authors' calculations and The Fiscal Analyzer

Appendix Figures 11 through 14 show Leia's total taxes paid, by tax category, for each career path. As in Table 1, the Child Tax Credit and Earned Income Tax Credit are included in public benefits and are thus not shown in appendix Figures 11 through 14. 


\section{Appendix Figure 11: Taxes for Concessions Career Path}

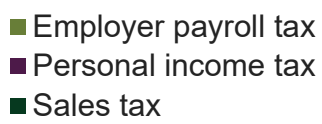

- Federal excise tax

- Federal insurance contributions act tax

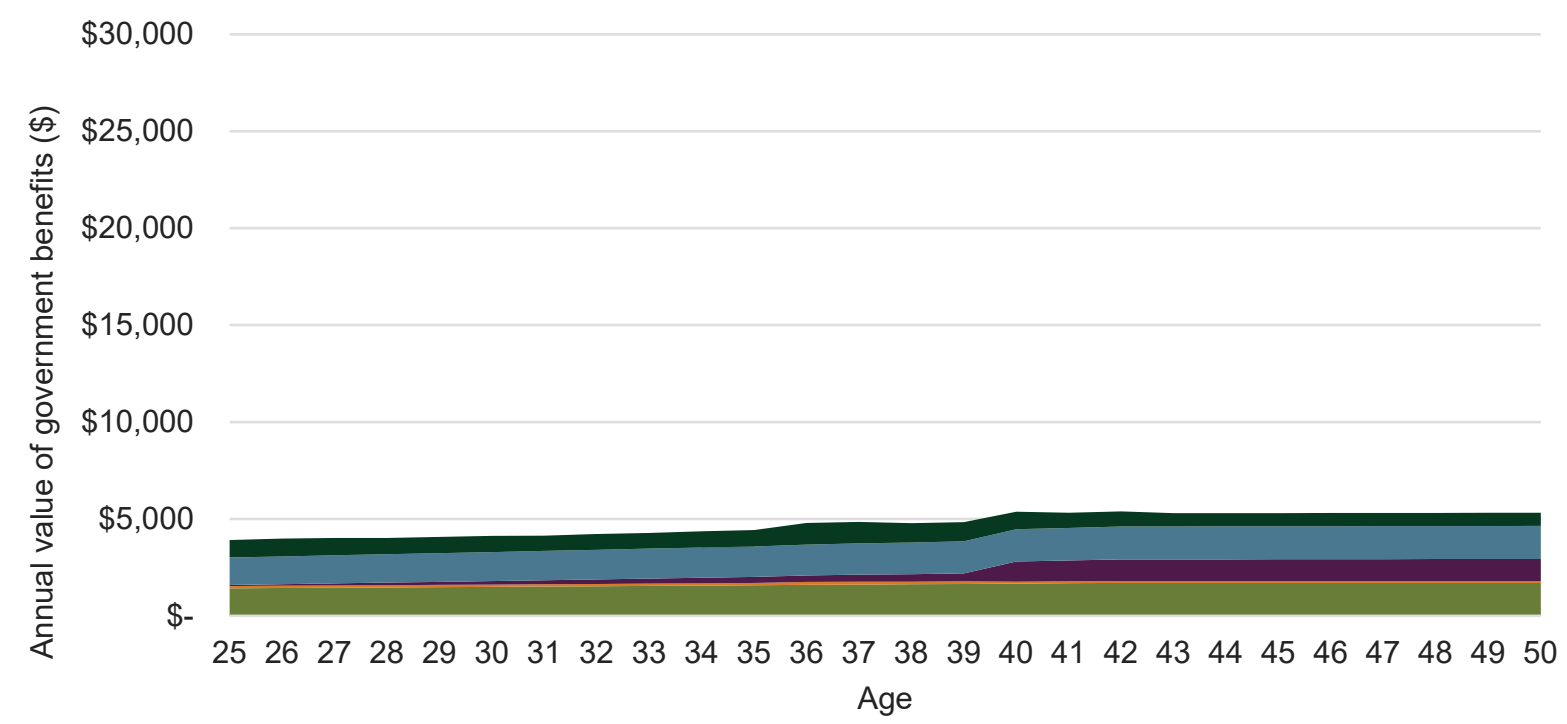

Sources: authors' calculations and The Fiscal Analyzer

\section{Appendix Figure 12: Taxes for CNA Career Path}

Employer payroll tax

- Personal income tax

- Sales tax
- Federal excise tax

- Federal insurance contributions act tax

$\$ 30,000$

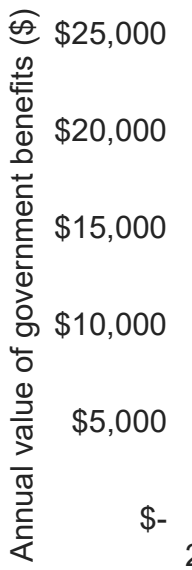

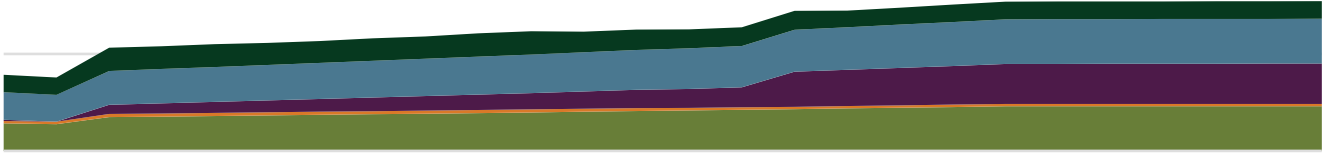

$\begin{array}{llllllllllllllllllllllllll}25 & 26 & 27 & 28 & 29 & 30 & 31 & 32 & 33 & 34 & 35 & 36 & 37 & 38 & 39 & 40 & 41 & 42 & 43 & 44 & 45 & 46 & 47 & 48 & 49 & 50\end{array}$ Age 


\section{Appendix Figure 13: Taxes for LPN Career Path}

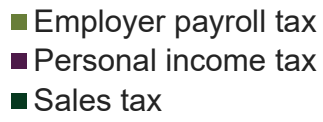

- Federal excise tax

- Federal insurance contributions act tax

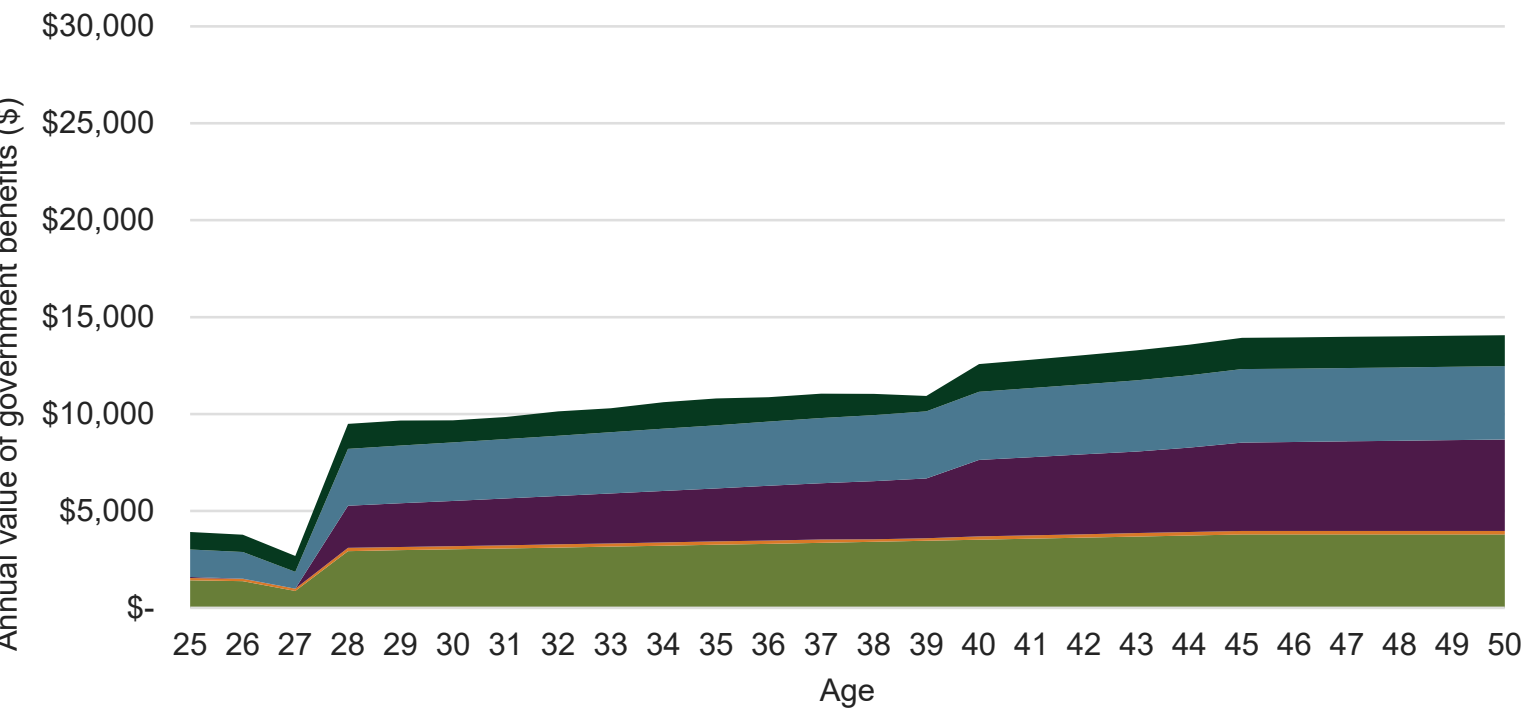

Sources: authors' calculations and The Fiscal Analyzer

\section{Appendix Figure 14: Taxes for RN Career Path}

- Employer payroll tax

- Personal income tax

- Sales tax
- Federal excise tax

- Federal insurance contributions act tax

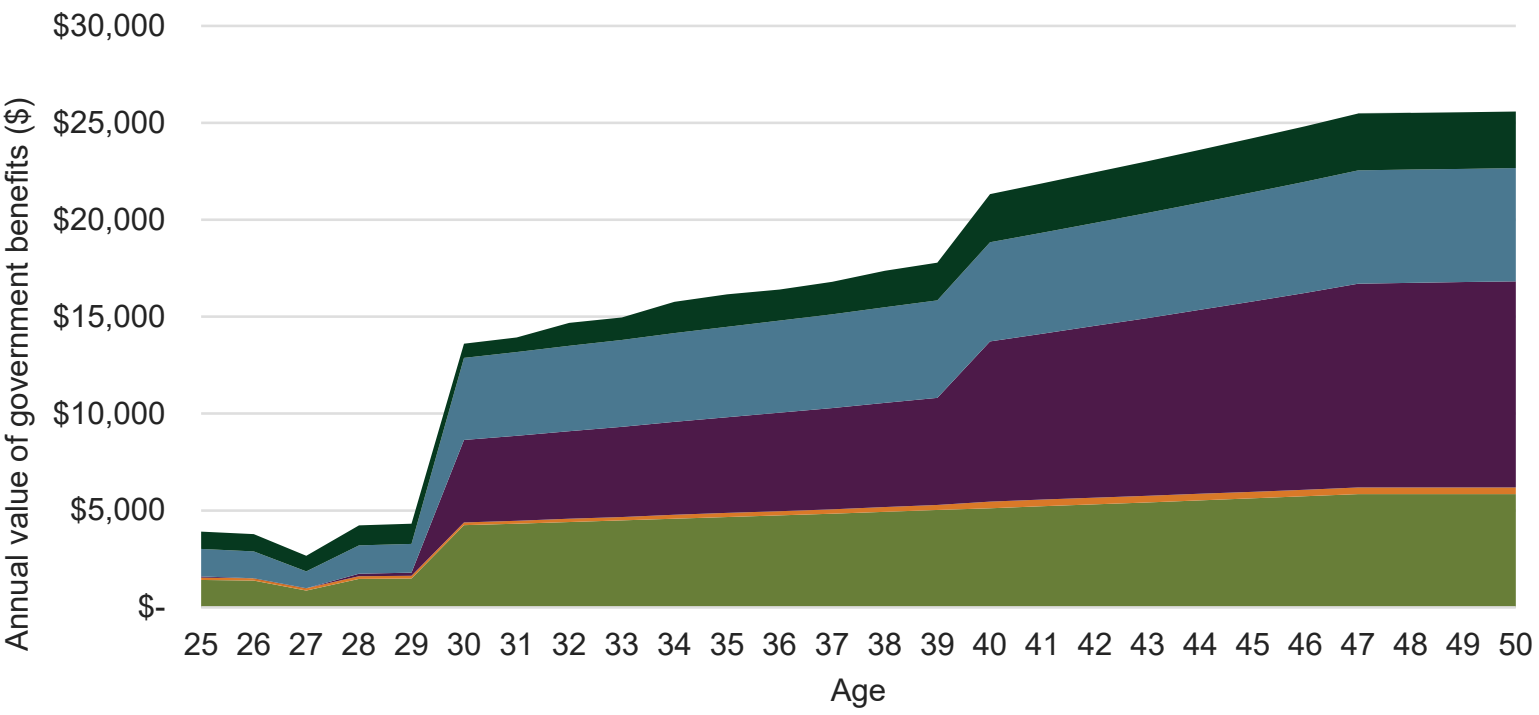

Sources: authors' calculations and The Fiscal Analyzer 


\section{Calculation of value of benefit programs and net expenses}

\section{Temporary Assistance for Needy Families (TANF)}

The TANF cash benefit amount is determined at the state level and is based on household size and income. In addition to cash distributions, states offer a variety of programs under their TANF systems. We only consider basic cash benefits and do not estimate the value of other transitional services (childcare, counseling, vehicle purchase, relocation) or cash incentives (such as for retaining a job). We assume individuals pass basic eligibility checks, which vary by state. For example, we assume respondents haven't been convicted of a drug felony, are not on strike, and haven't fraudulently claimed TANF benefits. Additionally, we assume individuals are fulfilling their work or training obligations as defined by their state. However, we assume that individuals do not qualify for hardship extensions to states' lifetime benefit limits. We use eligibility and benefit data compiled by the Urban Institute in the 2016 Welfare Rules Database (https://wrd.urban.org/wrd/Query/query.cfm).

\section{Food expense and Supplemental Nutritional Assistance Programs (SNAP)}

Total food expenses are estimated using the USDA Low-Cost Plan, which is the next-highest cost food plan compared to the Thrifty Food Plan. We use the Low-Cost Plan, given critiques that the Thrifty Food Plan underestimates the cost of a nutritionally adequate meal in the majority of U.S. counties (Waxman, Gundersen, and Thompson 2018). Plan prices vary by size of household and age of household members. For example, at age 25 when Leia's kids are four and six, we estimate her monthly food expenditures to be $\$ 583 .{ }^{37}$ The value of SNAP is simply the value of the vouchers provided. Eligibility for SNAP starts at a federally determined level based on income and family size, but states have the discretion to increase the income thresholds. The amount of the benefit declines gradually as income increases. Net food costs are simply the total cost of food minus the cash value of SNAP.

\section{Housing expense and federal rental assistance/subsidy}

In this case study, we assume that Leia is a renter and therefore may be eligible for federal rental assistance/subsidy. We assume Leia participates in the Section 8 Housing Choice Voucher Program. The total cost of housing is assumed to be the 2019 value of Fair Market Rent (FMR) in MiamiDade County, as established by the U.S. Department of Housing (HUD). The cost of FMR depends on the size of the family. For Leia, at age 25 with two kids, the FMR is $\$ 1,454$ per month. Later, when her kids

\footnotetext{
${ }^{37}$ The USDA data is available at www.cnpp.usda.gov/sites/default/files/CostofFoodJan2019.pdf. For household members 12 and older, we take an average of the male and female amounts. This assumes a family size of four, which has embedded in it economies of scale. If the household is only one person, the cost of the individual is 20 percent higher; for a two-person household, costs are 10 percent higher each; for a three-person household, costs are 5 percent higher. For a five- or six-person household, subtract 5 percent; and for seven or more people, subtract 10 percent.
} 
move out, we assume she switches to a one-bedroom apartment, paying $\$ 1,137$ per month. ${ }^{38}$ Housing vouchers have different rules for new enrollees versus continuing participants. New participants must have adjusted income below 50 percent of area median income $(\$ 38,150$ for a family of three) and continuing participants must have adjusted income below 80 percent of area median income $(\$ 61,000$ for a family of three). If the household is eligible, the value of the voucher will depend on the family's income. The household is expected to pay 30 percent of adjusted income toward rent, with the voucher covering the rest. Thus, the net housing expense will depend on the level of household income and on the cost of rent. While we assume she receives a Section 8 housing choice voucher, our analysis also applies to other HUD programs with identical eligibility rules, including public housing, Section 8 projectbased vouchers, Section 202 housing, and Section 811 housing.

\section{Health insurance expense and offsets}

The total cost of health care and the value of the benefit depend on the type of health insurance coverage. In our example, the options for health insurance are Medicaid, Medicare, health insurance purchased on the exchanges set up by the Affordable Care Act (ACA), employer-provided health insurance, and health insurance provided by the school Leia is attending. When deciding what type of health insurance she and her children have, we assume that she seeks to minimize the cost to her (or the "net" cost) as shown in Figure 1 and it is possible for her children to have a different type of coverage than her. The cost for each type of insurance (and associated offset) are described below. ${ }^{39}$

Health insurance through ACA Exchange: The total cost of health insurance purchased on exchanges set up by the Affordable Care Act is the state average cost of the second lowest-cost silver plan, adjusted for the participant's age. ${ }^{40}$ The value of the tax credit obtained under the ACA is a function of income (as a percentage of the federal poverty threshold) and the cost of the insurance plan on the exchange. Because the original design of the law called for an extension of Medicaid coverage up to 100 percent of the federal poverty threshold (which was not fully embraced by all states), the ACA tax credits are a bit different from other means-tested programs in that they start at the federal poverty threshold. Households with adjusted income between 100 and 133 percent of the poverty threshold pay at most 2 percent of their income in premiums, and this percent rises to as much as 9.5 percent for 300 to 400 percent of the poverty threshold. Thus, the net health insurance cost is the total cost of the

\footnotetext{
${ }^{38}$ Fair market values by MSA and county are available from www.huduser.gov/portal/datasets/fmr/fmr2019/FY2019 4050 FMRs rev2.xlsx. See www.huduser.gov/portal/datasets/fmr/fmrs/FY2019 code/select Geography.odn. Eligibility thresholds are at www.huduser.gov/portal/datasets/il/il2019/2019summary.odn.

${ }^{39}$ We follow the methodology used by the National Center for Children in Poverty's Family Resource Simulator (www.nccp.org/tools/frs/), which takes into account that health insurance costs vary by type of health insurance. ${ }^{40}$ Health insurance costs at the ZIP-code level come from the Kaiser Foundation, available at www.kff.org/interactive/subsidy-calculator/. We then aggregated up to the state level on a population-weighted basis. We made age adjustments using guidelines from Health and Human Services. See www.cms.gov/CCIIO/Resources/Regulations-and-Guidance/Downloads/Final-Guidance-Regarding-Age-Curves-andState-Reporting-12-16-16.pdf.
} 
health plan if purchased directly on the exchange minus the amount of the corresponding tax credit received.

Employer-sponsored health care: The total cost for employer-sponsored health insurance includes the part of the premium paid by the employer and the part of the premium paid by the employee. The data come from the Medical Expenditure Panel Survey and vary by number of people on the plan (individual, plus one, or family) but not by age. The net cost is the employee-paid portion of the health insurance. Not every career path will come with the option to purchase employer-sponsored health insurance. For this analysis, we assume the concessions occupation at the movie theater does not include this option, but the other occupations-CNA, LPN, and RN-do.

School-sponsored health care: We assume that the total cost of health care is included in school fees. Thus, the net cost to Leia is zero. Dependents are not covered under this plan. We assume that she is eligible for school-sponsored health insurance while she is enrolled full-time.

Medicaid: We calculate both the value of the benefit and the expense of Medicaid using statelevel data on the average cost per person. Thus, the net cost to the individual is zero. There are different eligibility rules for adults, adults with dependents, and children in Florida. In particular, the income threshold for children is higher than adults with dependents. Able-bodied nonelderly adults are not eligible for Medicaid in Florida at any income level. We take the detailed rules regarding each of these groups into account.

Medicare: Similar to Medicaid calculations, the total cost of Medicare is the average cost to the government of a Medicare participant. The premium that the individual pays differs by annual income. The value of the subsidy is the difference between the total cost and the premium that she pays. Individuals are eligible for Medicare starting at age 65.

Childcare expense and childcare assistance: Estimates of the total cost of childcare for Orlando, and Miami, Florida, come from a 2017 market rate survey done for each county in the state of Florida. The data reflect the 75th percentile of the market rate in Orange County and Miami-Dade County, respectively. To calculate the full-year costs, we assume that the six-year-old requires after-school care during the school year and full-time care during the summer, and the four-year-old requires full-year full-time care. Childcare costs in Mississippi come from data published by the National Association of Child Care Resource and Referral Agencies. Childcare assistance benefit programs are structured such that the parent or guardian pays a co-pay each time they use the service, and that co-pay rises with household income. Thus, to calculate the value of the benefit, we subtract the estimated cost from the co-pay amount. In Miami-Dade County, co-pays range from a few dollars to a few hundred dollars, depending on income level. In making these calculations, we incorporate second-child discounts that are relevant when both children need full-time care. Because the co-pay schedule does not gradually increase with income all the way up to the full cost of childcare, this results in a very large cliffs effect when it is lost. 


\section{References}

Abt Associates, Inc. 2014. "Pathways for Advancing Careers and Education (PACE) Evaluation Report." Abt Associates, Inc. OPRE Report \# 2014-76, Washington, DC: Office of Planning, Research and Evaluation, Administration for Children and Families, U.S. Department of Health and Human Services.

Albelda, Randy, and Michael Carr. 2017. "Cliff Effects in Massachusetts: Combining Earnings with Public Supports." Federal Reserve Bank of Boston, Community \& Banking, 2017 Series, Winter 2017.

Altig, David, Alan J. Auerbach, Patrick C. Higgins, Darryl R. Koehler, Laurence J. Kotlikoff, Michael Leiseca, Ellyn Terry, and Yifan Ye. 2019. "Did the 2017 Tax Reform Discriminate against Blue State Voters?" NBER Working Paper 25770.

Auerbach, Alan J., Laurence J. Kotlikoff, and Darryl R. Koehler. 2016. "US Inequality, Fiscal Progressivity, and Work Disincentives: An Intragenerational Accounting." NBER Working Paper 22032.

Auerbach, Alan J, Laurence J Kotlikoff, Darryl Koehler, and Manni Yu. 2017. "Is Uncle Sam Inducing the Elderly to Retire?" Tax Policy and the Economy 31 (1): 1-42.

Baker, Rachel, Eric Bettinger, Brian Jacob, and loana Marinescu. 2018. "The Effect of Labor Market Information on Community College Students' Major Choice." Economics of Education Review 65: 18-300.

Bingulac, Marija, Caitlin Carey, and Susan Crandall. 2017. "The Road to the Cliff Edge: Understanding Financial Gaps in Public Assistance Programs Available to Massachusetts Families." Center for Social Policy, University of Massachusetts Boston. Available at https://www.umb.edu/editor_uploads/images/centers_institutes/center_social_policy/The_Ro ad_to_the_Cliff_Edge_08.16.17.pdf. Last accessed March 9, 2019.

Bragg, Debra D., Barbara Endel, Nate Anderson, Lisa Soricone, and Erica Acevedo. 2019. "What Works for Adult Learners: Lessons from Career Pathways Evaluations." Jobs for the Future. Available at https://www.jff.org/resources/what-works-adult-learners-lessons-career-pathway-evaluations/. Last accessed September 10, 2019.

Brown, Alexandra, David Buchholz, Daniel Davis, and Arturo Gonzalez, eds. 2017. Economic Mobility: Research \& Ideas on Strengthening Families, Communities, and the Economy. St. Louis and Washington, DC: Federal Reserve Bank of St. Louis and the Board of Governors of the Federal Reserve System.

Butler, Stuart, William W. Bleach, and Paul Winfree. 2008. "Pathways to Economic Mobility: Key Indicators." The Economic Mobility Project, an Initiative of the Pew Charitable Trusts.

Camardelle, Alex. 2019. "Low Wages and Steep Cliffs: Recommendations to Eliminate the Cliff Effect in Georgia's Safety Net Programs." Georgia Budget \& Policy Institute Policy Report February 2019. Available at https://gbpi.org/wp-content/uploads/2019/03/Report-HighCostLowWagesSNAP.pdf. Last accessed March 9, 2019. 
Chetty, Raj, David Grusky, Maximilian Hell, Nathaniel Hendren, Robert Manduca, and Jimmy Narang. 2017. "The Fading American Dream: Trends in Absolute Income Mobility since 1940." Science 356 (6336): 398-406.

Chien, Nina. 2017. "Estimate of Child Care Eligibility and Receipt for Fiscal Year of 2013." ASPE Issue Brief. Washington: Office of the Assistant Secretary for Planning and Evaluation. Available at aspe.hhs.gov/system/files/pdf/258491/ChildCareSubsidyEligibility.pdf. Last accessed August 3, 2019.

Chien, Nina, and Suzanne Macartney. 2019. "What Happens When People Increase Their Earnings? Effective Marginal Tax Rates for Low-Income Households." Office of the Assistant Secretary for Planning \& Evaluation, U.S. Department of Health \& Human Services. Brief 2 in the ASPE Marginal Tax Rate Series.

Cielinski, Anna. 2019. "Career Pathways in Career and Technical Education." CLASP: Policy Brief January 2019.

Circles USA. 2018. "The Cliff Effect: A Summary of Advocacy and Policy Efforts." Circles USA. Available at www.circlesusa.org/wp-content/uploads/2018/06/Cliff-Effect-Research-by-Circles-USA.pdf. Last accessed October 9, 2019.

Congressional Budget Office. 2015. "Effective Marginal Tax Rates for Low- and Moderate-Income Workers in 2016." Congressional Budget Office. Available at www.cbo.gov/sites/default/files/114th-congress-2015-2016/reports/50923marginaltaxrates.pdf. Last accessed September 12, 2019.

Eyster, Lauren, and Semhar Gebrekristos. 2018. "Fulfilling the Promise of Career Pathways: Strategies That Support Career Advancement." Washington, DC: Urban Institute.

Florida Chamber Foundation. 2017. "Less Poverty, More Prosperity: The Florida Fiscal Cliffs Report." Florida Chamber Foundation, available at http://www.flchamber.com/wpcontent/uploads/2017/04/LessPovertyMoreProsperity_FLFiscalCliffsReport_Web.pdf. Last accessed March 9, 2019.

Florida Children's Council. 2018. "Two Generational Approach: Focused Policies for Improved Outcomes." "Two Generational Approach: Focused Policies for Improved Outcomes." Available at flchildrenscouncil.org/wp-content/uploads/FCC_Report_Web_04_18.pdf. Last accessed March 9, 2019.

Hastings, Justine, Christopher Neilson, and Seth Zimmerman. 2015. "The Effects of Earnings Disclosure on College Enrollment Decisions." National Bureau of Economic Research Working Paper 21300.

Jensen, Robert. 2010. "The (Perceived) Returns to Education and the Demand for Schooling." The Quarterly Journal of Economics 125 (2): 515-548. 
King, Christopher T., and Heath J. Prince. 2015. "Moving Sectoral and Career Pathway Programs from Promise to Scale." In Transforming Workforce Development Policies for the 21st Century, edited by Carl Van Horn, Tammy Edwards, and Todd Greene. Kalamazoo, Michigan: W.E. Upjohn Institute for Employment Research.

Loprest, Pamela, and Nathan Sick. 2018. "Career Prospects for Certified Nursing Assistants: Insights for Training Programs and Policymakers from the Health Profession Opportunity Grants (HPOG) Program." OPRE Report 2018-92, Washington, DC: Office of Planning, Research, and Evaluation, Administration for Children and Families, U.S. Department of Health and Human Services.

Loprest, Pamela, and Nathan Sick. 2019. "Health Professional Opportunity Grants 2.0: Year Three Annual Report." OPRE Report \# 2019-64. Washington, DC: Office of Planning, Research, and Evaluation, Administration for Children and Families, U.S. Department of Health and Human Services.

National Conference of State Legislatures. 2019. "Moving on Up: Helping Families Climb the Economic Ladder by Addressing Benefits Cliffs." National Conference of State Legislatures, in partnership with the Administration for Children and Families. Available at http://www.ncsl.org/research/human-services/addressing-benefits-cliffs.aspx. Last accessed September 10, 2019.

Romich, Jennifer L. 2006. "Difficult Calculations: Low-Income Workers and Marginal Tax Rates." Social Service Review 80 (1): 27-66.

Romich, Jennifer L., Jennifer Simmerlink, and Stephen D. Holt. 2007. "When Working Harder Does Not Pay: Low-Income Working Families, Tax Liabilities, and Benefits Reductions." Families in Society 88 (3): 418-426.

Rubinstein, Yona, and Yoram Weiss. 2007. "Post Schooling Wage Growth: Investment, Search and Learning." In Handbook of the Economics of Education, Volume 1, edited by Eric Hanushek and Finis Welch. Amsterdam: Elsevier.

Ruder, Alexander I., and Michelle Van Noy. 2017. "Knowledge of Earnings Risk and Major Choice: Evidence from an Information Experiment." Economics of Education Review 57: 80-90.

Seefeldt, Kristin S., Whitney Engstron, and Karen Gardiner. 2016. "Finances, Family, Materials, and Time: Career Pathways Participants' Perceived Challenges." OPRE Report 2016-28.

Waxman, Elaine, Craig Gundersen, and Megan Thompson. 2018. "How Far Do SNAP Benefits Fall Short of Covering the Cost of a Meal?" Urban Institute. Available at https://www.urban.org/sites/default/files/publication/96661/how_far_do_snap_benefits_fall_s hort_of_covering_the_cost_of_a_meal_4.pdf. Last accessed December 13, 2019.

Wiswall, Mathew, and Basit Zafar. 2015. "Determinants of College Major Choice: Identification Using an Information Experiment." Review of Economic Studies 82 (2): 791-824. 
Atlanta Fed Community \& Economic Development Discussion Paper Series • No. 01-20a

Wood, Natalie, Sarah Prendergast, Lindsey Vigoda, and Rich Jones. 2018. "A Look Past the Cliff." The Bell Policy Center. Available at www.bellpolicy.org/wp-content/uploads/2018/03/A-Look-Past-theCliff-March-2018.pdf. Last accessed March 9, 2019. 